\title{
ADOLESCENCIA, VARIACIÓN LINGÜÍSTICA, COMPETENCIA METACOMUNICATIVA Y ENSEÑANZA DE LA LENGUA
}

\author{
Antonio-M. Bañón Hernández \\ (Universidad de Murcia)
}

\begin{abstract}
RESUMEN
What we have aimed in the first part of the present paper is to carry out an analysis of some value judgement processes of linguistic variation from the evidence of two hundred and thirty-four Murcian adolescents registered in Compulsary Secondary Education Courses (ESO). Thus, we will both with the asumption of, adscription, adequacy, and adhesion to semio-linguistic habits - processes all related with maintenance attitudes--, and with the insiders' and outsiders' adversion to, accommodation to, and assimilation of semio-linguistic habits -processes all, on the other hand, following transformation attitudes. In the second part we will allude to some issues related with language teaching to nonstandard speakers or to non-standard-speaking communities.
\end{abstract}

\section{1.- A MODO DE INTRODUCCIÓN}

Las conexiones entre variación semiolingüística y discurso valorativo ocupan un destacado lugar en el análisis social del lenguaje. Nuestra intención, en el presente artículo, es identificar algunos de los procesos básicos que los adolescentes utilizan al valorar la variante dialectal seguida por los hablantes murcianos y reflexionar, posteriormente, sobre algunas constantes teóricas de la intervención didáctica en las tendencias de axiologización lingüística. La ausencia de investigaciones sobre las competencias comunicativas y textuales de los alumnos adolescentes, denunciada no hace mucho por Carmen R. García Fernández (1987: 89), la oportunidad, especialmente en el actual contexto de reforma 
educativa, de preguntar a profesores y alumnos, por separado, sobre sus actitudes hacia el dialecto local, requerimiento efectuado por Michael Stubbs (1987: 148), y la obligación del profesor de conocer y valorar las actitudes de los grupos sociales en donde ejerce o ejercerá su labor docente, recordatorio realizado, entre otros especialistas en Didáctica de la Lengua, por Sonsoles Fernández (1987: 57), avalarían, de entrada, la pertinencia, al menos, de trabajos como éste. Puesto que partiremos de testimonios de los propios adolescentes ${ }^{1}$, podemos decir que estamos, entonces, ante una investigación en torno a su competencia metacomunicativa y, en parte, también a su metacompetencia comunicativa. Sabemos que este estadio vital se aleja de etapas socio-cognitivas precedentes, entre otras cosas, por la consolidación paulatina de la capacidad de abstracción y la capacidad de metacognición (B. Inhelder-J. Piaget, 1985: 281-ss). Si admitimos la necesidad de combinar el estudio teórico de las competencias generales frente al mundo con las específicas, entre las que hay que incluir las habilidades sociocomunicativas (A. Fierro, 1985: 99), coincidiremos, igualmente, en que a la abstracción le corresponde la competencia metacomunicativa, la capacidad del adolescente para reflexionar sobre los usos y procesos de la comunicación real, mientras que a la metacognición le correspondería, en el ámbito de la Teoría del Discurso, la metacompetencia comunicativa, la capacidad para reflexionar sobre la competencia comunicativa propia y también sobre la ajena. «Durante la adolescencia — dice John H. Flavell (1984: 141) - la gente suele desarrollar una conciencia muy intensa tanto de sus propios procesos psicológicos como de los de los demás (metaconocimiento)».

Suzanne Romaine (1984: 84), precisamente, en su excelente trabajo The Language of Children and Adolescents. The Acquisition of Communicative Competence, nos dice, partiendo de la diversificación de interacciones durante la adolescencia, idea básica en los trabajos de Psicología Cognitiva y de Psicología Social, que, en torno a los trece, catorce y quince años, se observa un progreso evidente en la concienciación de la importancia social del lenguaje y en la asunción de valores en relación con la propia variación linguística. Estas palabras cobran mayor relevancia, si tenemos en cuenta que, como dice Alfredo Fierro (1990: 342), la adolescencia «no sólo es la edad en que se suele adherir a valores, sino que después de ella es infrecuente la conversión a un sistema diferente de valores. Es, por consiguiente, en estos años cuando va a definirse la orientación duradera que, por lo general, mantendrá durante el resto de su vida

\footnotetext{
1 La entrevista consistía en dos preguntas concretas: la primera preguntaba al adolescente si pensaba que en Murcia se hablaba bien o mal y la segunda si creía que él mismo hablaba bien o mal. El trabajo de recopilación de testimonios ha sido realizado por los siguientes profesores: M" Rosario Fernández Pérez, Rosa Penalva Moraga, Guadalupe Espantaleón Ortega, M Carmen Tébar Valenciano, Amparo Conesa Inglés, Aurelio Serrano Ortiz, Mㄹ Jesús Quintanilla Bernabeu, Miguel-Juan Cobacho López, M Soledad Castro Perlado, Alfonsa Muñiz García, Maruja Martínez García y Ana-Mª Pérez Zapilla. Desde aquí nuestro mas sincero agradecimiento a todos ellos.
} 
respecto a metas, a fines y a proyectos valiosos para ella y socialmente reconocidos». El análisis del lenguaje, sin ningún ginero de dudas, no puede ser ajeno a este contex to evolutivo; no en vano, Richard R. Day (1982: 116) considera las actitudes un componente fundamental en el estudio de la competencia comunicativa.

El discurso valorativo, naturalmente, difiere, según atendamos a unos testigos o a otros, en el grado de intensidad e implicación, en la dimensión actitudinal elegida y en los ámbitos sometidos a consideración axiológica. Así, por ejemplo, no es igual un discurso mas o menos inhibido, que evita responsabilizarse de las causas y consecuencias de los sucesos que constata, que un discurso comprometido en mayor o menor medida, que opta con claridad por la defensa de ciertas valoraciones. Las dimensiones analizadas pueden ser las centradas en la vertiente afectiva o en la vertiente cognitiva. Por otra parte, mostrar determinadas actitudes al opinar ${ }^{2}$ sobre la adquisición de hábitos semiolingüísticos ${ }^{3}$ no es igual que hacerlo sobre tendencias comportamentales o sobre comportamientos reales referentes a conservación o transformación. De hecho, el discurso de los adolescentes consultados confirma la existencia de una tensión actitudinal en torno a estos dos procesos opuestos, que no es sino un fiel reflejo de las inevitables tensiones del sistema cultural, social y semiolingüístico (Cidmar T. Pais, 1983).

Partimos de un modelo de ocho procesos de los que cuatro participan de los intereses conservadores y cuatro de los intereses transformadores. Entre todos estos procesos pueden hallarse algunos aspectos comunes, pero sus diferencias no son menos evidentes:

\section{VARIACIÓN SEMIOLINGÜÍSTICA Y DISCURSO VALORATIVO.}

\section{TENSIÓN ENTRE PROCESOS ACTITUDINALES}

\section{CONSERVACIÓN SEMIOLINGÜÍSTICA Y SOCIOSEMIÓTICA}

1. Asunción de hábitos semiolinguíísticos y sociosemióticos

2. Adscripción a hábitos semiolingüísticos y sociosemióticos

3. Adecuación a hábitos semiolingüísticos y sociosemióticos

4. Adhesión a hábitos semiolinguísticos y sociosemióticos

2 «Opinión es la expresión verbal de una actitud». Daniel Katz (1982:265).

3 Utilizamos el término hábitos semiolingüísticos como concepto genérico, aunque sabemos que, en algunos procesos cabría hablar, mejor, de modelos, de costumbres, etc. Cfr. «Los hábitos verbales», de Pierre Oliron (1969). 


\section{II.TRANSFORMACIÓN SEMIOLINGÜÍSTICA Y SOCIOSEMIÓTICA}

5. Adversión hacia hábitos semiolingüísticos y socios. endogrupales

6. Adversión hacia hábitos semiolingüísticos y socios. exogrupales

7. Acomodación a hábitos semiolingüísticos y sociosemísticos

8. Asimilación a hábitos semiolinguiísticos y sociosemióticos

Esta complejidad procesual, por lo demás, es la confirmación no sólo de la propia complejidad de la competencia metacomunicativa de este segmento de población, sino también del largo camino que queda por recorrer, en nuestra opinión, en lo que se refiere a las investigaciones interdisciplinares que centran sus intereses en el lenguaje.

\section{2.- ASUNCIÓN DE HÁBITOS SEMIOLINGÜÍSTICOS Y SOCIOSE- MIÓTICOS}

El proceso de asunción se basa en la creencia ${ }^{4}$ de que el hablante, quiera o no, se contagia de los malos hábitos comunicativos de quienes le rodean y nada puede hacerse para evitar esta circunstancia. La adopción y el desarrollo de una variante lingüística se ve, entonces, desde esta perspectiva, como una réplica directa de determinados hábitos y modelos comunicativos que son, pues, recibidos y posteriormente emitidos, sin mas. La mera exposición al lenguaje producida en un determinado ambiente conduce inevitablemente a la asunción de esos hábitos semiolingüísticos y a su posterior reproducción en el contexto de modelos sociosemióticos que acaban por conservarse. Asunción y reproducción conforman el procedimiento menos costoso en lo que se refiere a la adquisición y al posterior aprovechamiento de prototipos comportamentales de comunicación. Sin embargo, sm genera un coste en cuanto a valoración del producto lingüístico adquirido. En efecto, desde esta perspectiva, asunción y reproducción son valoradas negativamente, al concebirse como contagio del que no se es, en última instancia, responsable. La exposición acaba siendo interpretada como imposición de hábitos y modelos semióticos: «Hablo mal, porque algunas cosas las digo regular, por lo que oigo» (T.30). «Si una persona esta junto a otra que habla mal, esa persona se va a costumbrando a hablar mal» (T.113). «Hablo mal, porque se me pega la pronunciación que utiliza mucha gente y que habla mal» (T.165). «Hablo regular, porque se me pega lo malo» (T.190). «Yo creo que hablo regular, sin vulgarismos, pero con terminaciones inadecuadas, porque lo malo se pega» (T.199). «Hablo mal, porque estamos acostumbrados a decir lo

4 Las creencias «son los elementos que describen el objeto de la actitud, sus características y sus relaciones con otros objetos» (Daniel Katz, 1982: 265). 
que escuchamos y cómo se dice lo que escuchamos» (T.204). «Con el trato diario se adoptan las expresiones en todas sus formas, ya sean correctas o incorrectas» (T.207). En este sentido, sólo el aislamiento relativo frente al ambiente y los patrones lingüísticos que ofrece puede preservar del contagio: «Yo hablo bien, porque la gente dice cosas y yo paso de todo» (T.26). «Intento no verme influenciado por el habla del barrio, la clase social, etc. de donde vivo» (T.116). «Yo hablo peor que mis padres, porque ellos no han tomado palabras de la sociedad» (T.203). «Mis padres hablan bastante mejor que yo. Tal vez sea sólo por motivo de la edad y porque ellos no salen a la calle» (T.212). «Mis padres hablan mejor, porque a ellos no se les ha contagiado mucho el acento murciano» (T.196).

Nos encontramos, en definitiva, un sujeto paciente cuya misión fundamental no es otra mas que recibir, interiorizar y automatizar los patrones comunicativos ofrecidos por sus interlocutores mas habituales, cediendo a los supuestos generadores del contagio cualesquiera otras responsabilidades en el proceso de conservación de una variante lingüística. Ahora bien, el discurso de los testigos entrevistados puede trascender, lógicamente, a aspectos mas específicos, como es la selección de referentes comunicativos que intervienen como actores en el proceso de imposición. He aquí la taxonomía de referentes citados por los testigos:

\section{EXPOSICIÓN AL LENGUAJE-IMPOSICIÓN DE HÁBITOS COMUNICATIVOS «ME CONTAGIO DE COMO HABLA $(x)$ O DE COMO SE HABLA EN $(x) »$}

\section{TESTIGOS REFERENTES LINGÜÍSTICOS NEGATIVOS $(x)$}

10 gente que me rodea

11 la gente

14 los demás

22 personas mayores

24 nuestra familia

35 otros

37 el pueblo

42 el pueblo

44 todo el mundo personas que te rodean la gente las otras personas nuestros contornos mi entorno la gente que me rodea mis compañeros

138 todo el mundo que me rodea

140 personas mayores

147 gente con la que convives 
ambiente

personas de tu alrededor esta zona de la región las demás personas mis amigos mis padres

Llama la atención, especialmente, el papel que desempeña el modelo lingüístico adulto en la imposición de constantes comunicativas valoradas negativamente. La manera de hablar de la familia, en general, o de los padres, en particular, es evocada como transmisora de hábitos y modelos lingüísticos poco apropiados. Si tenemos en cuenta que, en bastantes ocasiones, se cita, en este mismo contex to axiológico, la mediación de referentes tales como gente mayor o personas mayores, parece clara la existencia, en la estructura de pensamiento metacomunicativo de algunos adolescentes, de una disfunción entre lo que dicho modelo adulto les ofrece y lo que en verdad debiera ofrecerles.

También puede suceder que, en lugar de la mediación discursiva de un único referente, nos encontremos con la selección de varios modelos que o bien cooperan e intensifican la imposición de hábitos, o bien se oponen entre sí, de tal manera que uno se erige en representante de los malos hábitos semiolingüísticos y otro en atenuante o equilibrador de los mismos. Cuando no se alude a una jerarquización entre los miembros de la oposición (es decir, cuando no se menciona un modelo semiótico vencedor sobre otros), podemos hablar de compensación, pero cuando esa jerarquización existe, es cuando hablarmamos de oposición stricto sensu.

\section{EXPOSICIÓN AL LENGUAJE-IMPOSICIÓN DE HÁBITOS COMUNICATIVOS ARGUMENTOS-COMBINACIÓN: OPOSICIÓN:}

$<$ PUEDE MÁS EL CONTAGIO DE (x), QUE EL MODELO OFRECIDO POR (y)> COMPENSACIÓN:

$<$ ME CONTAGIO DEL HABLA DE $(x)$, PERO TAMBIÉN SIGO

EL HABLA DE $(y)>$

COLABORACIÓN:

$<$ ME CONTAGIO DEL HABLA DE (x1) Y TAMBIÉN DEL HABLA DE (x2)> 


$\begin{array}{clll}6 & \text { oposición } & \text { familia } & \text { escuela } \\ 8 & \text { oposición } & \text { ambiente cotidiano } & \text { escuela } \\ 33 & \text { oposición } & \text { calle } & \text { escuela } \\ 39 & \text { oposición } & \text { huerta } & \text { escuela } \\ 83 & \text { oposición } & \text { amigos } & \text { familia } \\ 200 & \text { oposición } & \text { ambiente } & \text { casa } \\ 208 & \text { oposición } & \text { sociedad } & \text { padres } \\ 232 & \text { oposición } & \text { calle } & \text { padres } \\ 186 & \text { oposición } & \text { educación de calle } & \text { educación } \\ 151 & \text { oposición } & \text { mundo que rodea } & \text { educación } \\ 77 & \text { compensación } & \text { familia } & \text { escuela } \\ 117 & \text { compensación } & \text { familia } & \text { escuela } \\ 108 & \text { colaboración } & \text { familia-amigos } & \\ 132 & \text { colaboración } & \text { calle-amigos } & \\ 215 & \text { colaboración } & \text { casa-pueblo } & \end{array}$

En este contex to hemos de decir que los medios de comunicación audiovisual ejercen una poderosa presión psicosocial sobre su audiencia y son responsables, en parte, según los adolescentes, del contagio de malos hábitos, especialmente entre los jóvenes: «Vemos mucho la televisión y en ella se dicen palabras tontas y a nosotros se nos quedan grabadas en la memoria y luego las decimos» (T.112), «La televisión nos hace muchas veces dudar de lo que es correcto, y pensamos que copiando ese lenguaje no nos equivocamos» (T.116), «Ahora cometemos mas errores al hablar, porque los medios de comunicación (especialmente la televisión) nos transmiten fallos que antes no se daban aquí» (T.118), «Yo hablo mal, porque veo mucho la tele y en la calle oigo muchas cosas malas» (T.227). Entre esos malos hábitos se destaca, en ocasiones, los extranjerismos contaminadores: «Ahora, con la televisión y los espacios que en ella aparecen (programas y culebrones) nos vemos mas confundidos en cuando al vocabulario. Hay mas contaminación de palabras ajenas a nuestra lengua» (T.116), «La juventud, sobre todo, acepta mucha influencia de los medios de comunicación y se utilizan muchos vocablos extranjeros» (T.205), «Todo lo de la televisión, como los culebrones, nos esta contaminando» (T.119). La autoridad del modelo linguístico televisivo es evidente: "Se habla regular, al estar comunicándose con la tele, en la que hay programas que no hablan bien o usan palabras incorrectamente» (T.111), «Algunas veces cometemos errores por culpa de la televisión, que influye mucho en todos nosotros» (T.121). Incluso se insinúa su labor como lamentable sustituta de la formación académica: «En Murcia se habla regular, porque hay mucha gente que no ha ido al colegio y que se ha fijado en el idioma de la tele» (T.120). El lenguaje televisivo puede identificarse con el modelo personal de ciertos presentadores: «Una causa por la 
que la gente habla mal es debido a los medios de comunicación, porque, al hablar, los presentadores cometen errores; entonces, la gente, e incluso yo, creemos que esta bien, y cometemos sus mismos errores» (T.122). Como advertíamos con anterioridad, el distanciamiento del foco de contagio es el mejor procedimiento para preservarse del mismo: «Mis padres hablan mejor que yo, ya que los errores que yo tengo son la mayoría por influencia de la televisión y mis padres no suelen tenerlos» (T.103).

\section{3.- ADSCRIPCIÓN A HÁBITOS SEMIOLINGÜÍSTICOS Y SOCIO- SEMIÓTICOS}

El discurso de la adscripción semiótica se basa en la creencia de que el habla de Murcia es mala, pero legítima o apropiada al contexto. Los testigos que defienden esta premisa aceptan una mayor implicación en los procesos que describen, pero su deseo de evitar conflictos deriva en una cierta inseguridad lingüística, es decir, una disfunción entre el cómo se valora una variante linguística y la actuación comunicativa concreta de quien hace esa valoración (F. García Marcos, 1993: 43). En efecto, se intenta mantener un difícil equilibrio entre la valoración negativa de su variante o de la de quienes le rodean y la justificación de la existencia de esa misma variante y de sí mismo como usuario real o potencial de ella. La inseguridad lingüística puede conducir, en ocasiones, a disfunciones argumentales próximas a la esquizofrenia actitudinal. Unas veces muestran duda: «Creo que en Murcia se habla mal, aunque esto no es totalmente cierto ya que cada zona de España tiene sus propias connotaciones culturales y debe mantenerse, pero esto no quita que en Murcia haya veces que al hablar no se utilice correctamente el lenguaje» (T.20), «Sí se habla bien, porque mientras se entienda lo que decimos, hablamos bien, aunque debo decir que no somos muy buenos hablando» (T.41), «Regular, porque es nuestra forma de hablar, y no porque no pronunciemos las «s»o algunas terminaciones eso no quiere decir que hablemos mal, aunque sí tenemos muchos fallos al hacerlo» (T.55), «Pienso que la mayoría de la gente de aquí habla mal, porque entre otras cosas, en Murcia, mas que en Madrid, se tienen algunas acepciones, aunque ello no signifique hablar mal» (T.102), «Yo creo que no se habla mal, porque cada región tiene sus características, aunque ésta sea de las que mas errores tiene» (T.107). Y otras abierta contradicción: «En Murcia se habla fatal. Nos comemos todos las «s» finales y no finales, aunque relativamente hablamos bien; simplemente son las «s»» (T.184).

Estos adolescentes asumen, de entrada, los cánones y estereotipos supuestamente prestigiosos que critican las variantes lingüísticas no-estandares, lo que supone, en realidad, seguir la tendencia hacia la homogeneización actitudinal, tal y como ha sido destacada por Michael A. K. Halliday (1982: 207): «Hay cierta 
tendencia a convergir, pero no en el propio lenguaje, sino en las actitudes hacia él: la gente comparte cada vez mas las mismas evaluaciones del habla de los demás y de su propia habla», o por Michael Gregory y Susanne Carroll (1986: 42): «Las pruebas psicológicas recientes han mostrado que las actitudes lingüísticas respecto de las variables socialmente significativas están generalizadas en toda la comunidad. Los hablantes que usan variables estigmatizadas parecen no darse cuenta de esto y tienen las mismas actitudes negativas ante su propio lenguaje que los otros hablantes». Algunos testigos incluso ven el mal-hablar como una característica innata de la variante que valoran: «Se habla bien, pero un poco a lo bruto, porque así es el murciano» (T.51), «Yo creo que se habla un poco mal, y creo que porque es el lenguaje típico de esta región» (T.54), «Se habla mal, pero hay que tener en cuenta que es nuestro dialecto» (T.183). Esto no implica el rechazo de la función integradora, desde el punto de vista sociosemiótico, que el uso de la variante le ofrece al interlocutor. La integración en el sistema simbólico de un colectivo proporciona una especie de salvaguarda para quienes se adecúan a sus hábitos comunicativos. Ocurre, sin embargo, que esa integración es entendida, a veces, como obligación antes que como opción, como DEBER HACER antes que como QUERER HACER: «Me gustaría hablar mejor, pero debo seguir hablando como en mi pueblo se habla» (T.41). Vivir en un determinado lugar implica pertenecer a un grupo y hablar de determinada manera: «Hablo mal porque yo me he criado en la huerta y soy huertano, aunque no quieras» (T.31), «Hablo mal, porque hablo como se habla en Murcia» (T.32), «Yo creo que hablo mal, porque hablo como el resto de los murcianos» (T.149), «Yo hablo mal, porque en Murcia se habla así, y yo hablo así» (T.167), «Hablo mal, porque hablo igual que la gente que me rodea» (T.197), «Como en Murcia se habla mal y yo soy de Murcia, hablo igual que todos los de Murcia» (T.198). $\mathrm{Y}$ esto aunque esa manera de hablar sea valorada negativamente y aunque la escuela proponga modelos lingüísticos alternativos: «Hablamos mal, porque, aunque los maestros nos enseñen, es nuestra manera de hablar» (T.226).

Digamos, finalmente, que la autoestima resulta fundamental en el desarrollo socioafectivo del adolescente. Esta depende, en gran medida, de las interacciones con los compañeros (A. Fierro, 1985: 126), puesto que son los iguales quienes comienzan a ejercer paulatinamente mayor presión en actitudes y comportamientos, sobre todo a partir de la llamada adolescencia media, según recuerda J. Roy Hopkins (1987: 236). Las jergas juveniles (endocomunicación juvenil) forman parte de la integración grupal: «Nosotros muchas veces no usamos el lenguaje con toda la propiedad que debiéramos usarlo porque usamos las jergas» (T.206). Además, hablar mal puede ser una forma de conseguir un estatus ventajoso en la dinámica interna de un grupo de adolescentes, como nos viene a decir T.125: «Yo, cuando salgo con los amigos a darme una vuelta, hablo mal para chulear con los amigos». 


\section{4.-ADECUACIÓN A HÁBITOS SEMIOLINGÜÍSTICOS Y SOCIO- SEMIÓTICOS}

Siempre que constatemos la normalización de una determinada variante lingüística, arguyendo que las diferencias en el hablar nunca pueden ser equivalentes a deficiencias comunicativas ( Ser de Murcia no significa hablar mal», T.158), estaremos ante lo que hemos llamado adecuación a hábitos semiolingüísticos. Los adolescentes que sufren u observan algún tipo de disfunción linguística conocen perfectamente esta distinción y, en algunos casos, destacan las consecuencias sociales que las deficiencia conllevan (en concreto se menciona el rotacismo, la disfemia y la utilización de muletillas fónicas): «Me parece que con la edad que tengo, no hablo bien del todo, porque no si pronunciar bien algunas palabras y tengo un defecto de pronunciación en la [r]» (T.62), «Algunos hablan mal y la gente se ríe de ellos» (T.101), «Hablo mal, porque suelo añadirles a las palabras una consonante que no lleva» (T.152), «Hablo mal, porque no pronuncio la [r]》 (T.163), «Cuando estoy hablando con algún chico o chica, hablo bien, aunque tartamudeo un poco y me dicen algunos chicos que hablo mal» (T.234)

Desde el punto de vista sociocomunicativo el proceso de adecuación supone una racionalización de las actitudes hacia la variación linguística y un nuevo aumento en el grado de implicación discursiva y de identificación de / con el sistena comunicativo de un colectivo geosocial. En este sentido, resultaría rentable, en nuestra opinión, la mediación de conceptos tales como prototipicidad o incertidumbre cognoscitiva. Los hábitos linguísticos conforman prototipos de interacción a partir de los cuales es posible identificar, ser identificado ( $\ll$ Se habla bien. Así nos reconocen en todo lados», T.191) y, finalmente, evaluar las necesidades de adaptación comunicativa. Desde el ámbito de la Sociolingüística, Richard Anthony Hudson (1982: 207-208) afirma: «No resulta difícil de comprender el por qué la gente utiliza el habla como fuente de información acerca de las características sociales del hablante. La necesidad de tal información se plantea con el encuentro de un extraño, cuando uno tiene que relacionarse con él o calcular su credibilidad. En ambos casos, es importante el conocer algo acerca de la otra persona con el fin de planificar el propio comportamiento (...). Esta necesidad básica de información sobre la otra persona se ha denominado incertidumbre cognoscitiva, alrededor de la cual se ha elabo-rado una teoría por un grupo de psicólogos sociales (...). Podemos ubicar esta teoría dentro de otra

Las revistas editadas por los propios centros educativos suelen incluir cartas y artículos de adolescentes en los que aparecen reflexiones y denuncias muy interesantes a propósito de los sentimientos que se generan entre los que sufren algún tipo de disfunción linguística. Nos gustaría resaltar, por ejemplo, el $n^{\circ} 0$ de la revista La Noria (otoño de 1992), del Instituto de Bachillerato Francisco Salzillo de Alcantarilla (Murcia), en el que aparece un artículo de una niña disfémica bajo el rítulo «De no hablarme hasta no dejarme participar en clase». 
mucho mas general concerniente a los prototipos. Una de las razones por las que los humanos muestran esta inclinación a hacer uso de los prototipos es la de que necesitan con rapidez una información que, de otro modo, les sería inaccesible, de modo que puedan utilizarla para planificar su comportamiento».

Además del reconocimiento de la legitimidad de lo diverso, al margen de axiologizaciones innecesarias, los adolescentes se ocupan, a veces, de la entidad diatópica que delimita las fronteras en la variación lingüística y de la etiqueta que define el conjunto de características linguísticas propias. He aquí algunos ejemplos:

«SE HABLA BIEN, NORMAL, DIFERENTE, PORQUE CADA $(x)$ TIENE SU $(y) »$

\begin{tabular}{|c|c|c|}
\hline TESTIGOS & ENTIDAD DIATÓPICA (x) & ETIQUETA DEFINIDORA (y) \\
\hline 5 & región & forma de hablar \\
\hline 16 & lugar-comunidad & castellano diferente \\
\hline 18 & región & características lingǘsticas \\
\hline 19 & pueblo-comunidad & manera de expresarse \\
\hline 29 & lugar & manera de hablar \\
\hline 50 & comunidad & forma de hablar \\
\hline 61 & lugar & acento \\
\hline 62 & sitio & forma de hablar-acento \\
\hline 63 & ciudad & modo de hablar \\
\hline 65 & región & habla y pronunciación \\
\hline 66 & provincias & manera de hablar \\
\hline 69 & lugar & hablar \\
\hline 70 & ciudad-capital & dialecto-acento \\
\hline 96 & región-provincia & manera de hablar \\
\hline 155 & ciudad & manera de hablar \\
\hline 162 & región & dialecto \\
\hline 177 & ciudad-región & forma de hablar \\
\hline
\end{tabular}

\section{5.- ADHESIÓN A HÁBITOS SEMIOLINGÜÍSTICOS Y SOCIO- SEMIÓTICOS}

La adhesión, proceso citado por algunos psicólogos sociales que estudian las actitudes (por ejemplo por D. Krech et alt., 1978: 201), representa el mayor grado de aproximación entre el sujeto que valora una variante lingüística y esa misma variante. Como dice Richard A. Hudson (1982: 210), a la gente le gusta pensar que pertenece a un grupo supuestamente valioso, lo que, además, tiene consecuencias inmediatas en la generación de prejuicios lingüísticos, toda vez que la valoración positiva de una variante suele implicar, por desgracia, no sólo la valoración negativa de otra, sino también de sus usuarios habituales (H. Giles -P. Smith, 1979: 52). Este desequilibrio genera, irremediablemente, actitudes extremas, y lo que, en principio, podría ser sólo un sentimiento de identificación grupal a través del lenguaje, pasa a ser un enfrentamiento, velado o no, de 
modelos sociosemióticos. El modelo perdedor (o sea, el que no pertenece al grupo de hablantes que siguen patrones comunicativos con mayor prestigio social) reivindicará sus derechos ante los agentes sociales que le descalifican.

La endocomunicación es un típica reacción de los hablantes no-estandares que se adhieren a sus hábitos comunicativos. Consiste en restringir las posibilidades de interacción entre locutores pertenecientes a distintos grupos lingüísticos como procedimiento de revitalización de la fidelidad al grupo y de reivindicación del modelo comunicativo alternativo: «Creo que hablamos bien. Nosotros nos entendemos» (T.21), «Los murcianos hablamos como sabemos, y si no pronunciamos bien las «s», que no nos escuchen» (T.67), «Yo creo que hablo de puta madre, porque en Murcia siempre nos entendemos» (T.169). Esta actitud puede repercutir en el horizonte lingüístico-descriptivo del adolescente hasta tal punto que crea no hablar castellano: «Yo creo que hablo bien, porque yo no hablo castellano, sino murciano» (T.68).

La identificación extrema entre grupo social y lenguaje se resuelve en el caso de nuestros adolescentes en dos orientaciones argumentales fundamentales: la primera defiende que SER BUEN MURCIANO IMPLICA HABLAR COMO LOS MURCIANOS, al margen de la aceptación o no de las valoraciones más extendidas con respecto a la variante no-estandar de que se trate. En efecto, puede darse el caso de que se acepte la valoración negativa de la variante pero que se sobreponga a la misma el sentimiento de fidelidad grupal: «Yo hablo mal por el simple hecho de ser murciano, y como buen murciano tengo que hablar como los murcianos y a ver quién se atreve a decir lo contrario» (T.154). La segunda mantiene que SER BUEN MURCIANO IMPLICA DECIR QUE LOS MURCIANOS HABLAN SIEMPRE BIEN: «Yo creo que se habla bien, porque los murcianos siempre hablan bien, y el que diga lo contrario es que no es murciano» (T.169), «En Murcia se habla bien. Yo defiendo al pueblo de Murcia» (T.142).

En dos de los tres últimos testimonios reproducidos observamos que los adolescentes murcianos se sirven de una fórmula reivindicativa por excelencia: la contra argumentación (cfr. K. K. Reardon, 1983: 137); es decir, la réplica a lo que se dice o se pudiera decir por los que se sabe que no opinan lo mismo. Es esta referencia al discurso de los otros lo que, en muchas ocasiones, diferencia la adhesión y la reivindicación de otros procesos de conservación semiótica. Como hemos visto, la contra argumentación puede aparecer como provocación explícita, aunque lo normal es que no sea así: "Yo hablo como se habla en mi región, aunque en otros lugares nos criticarían por nuestra forma de hablar» (T.181), «Si las demás regiones creen que somos brutos, peor para ellos. Los brutos son los que critican a los demás» (T.21), «Creo que se habla bastante bien, no como nos tachan en otras comunidades españolas» (T.188).

La adhesión a hábitos semiolinguiísticos es el ejemplo mas significativo de una de las funciones básicas de las actitudes: la expresiva-defensiva (J. Escamez 
- P. Ortega, 1993: 52). El adolescente se implica afectivamente y establece conexiones entre lenguaje, cultura y herencia filogenética, cosa por lo demás harto frecuente a la hora de realizar manifestaciones de índole sociolingüística. Mantener el lenguaje significa mantener la cultura y las tradiciones, y, viceversa, mantener la cultura y las tradiciones supone mantener el lenguaje, tal y como afirma Wallace E. Lambert (1979: 187). El respeto es un término básico en esta red conceptual: «Hablo bien, porque el panocho es un lenguaje igual que el catalán o el valenciano y a mm me gusta porque es el que me enseñaron mis padres; por eso lo respeto» (T.21), «Se habla bien, porque cada comunidad autónoma habla como hablaron sus antepasados» (T.168), «Hablo bien, porque mis padres me han enseñado este habla, el cual todos los murcianos lo deben respetar tal y como es» (T.170), «Creo que se habla una lengua local que hay que respetar, igual que la lengua oficial. Por lo tanto creo que se habla bien» (T.210).

Hablar mal puede no tener tanta importancia si, a cambio, se muestran otros valores, como la sinceridad o la laboriosidad. Dicen Michael Gregory y Susanne Carroll (1986: 42): «Mientras que los hablantes pueden devaluar su propio dialecto respecto de los valores de «actuación» (éxito personal, movilidad de ascenso, competencia, etc.), pueden atribuir valores «éticos» positivos a los mismos marcadores (valores como honestidad, rudeza, fuerza o sinceridad, entre otros). Así pues, esta diferenciación puede contribuir para reforzar la identificación y la lealtad dentro de los grupos». Esta es una muestra de valoración implícita o prestigio encubierto: «Hablamos bien porque decimos lo que sentimos o la verdad, aunque la lengua sea panocho» (T.28), «En Murcia se habla mal, porque Murcia ha sido toda la vida muy trabajadora; ha tenido que trabajar en la huerta de sol a sol para ganarse el pan» (T.167).

\section{6.- ADVERSIÓN HACIA HÁBITOS SEMIOLINGÜÍSTICOS Y SOCIO- SEMIÓTICOS ENDOGRUPALES}

Pasamos ya a la tendencia hacia la transformación semiótica y lo hacemos mediante el proceso de adversión de los adolescentes murcianos hacia los hábitos semiolingüísticos del habla de su comunidad; adversión que puede ser planteada con extrema dureza y con un determinismo especialmente llamativo: «Casi toda la gente que ha nacido en Murcia lleva en la sangre el hablar mal» (T.166), o con un grado de certidumbre y absolutismo no menos exagerado: «Se habla mal, porque los murcianos siempre hemos hablado mal» (T.225), «Creo que en Murcia no se habla bien, porque los murcianos desde siempre hemos sido bastos. No sabemos expresarnos» (T.72).

EI reconocimiento social y la transmisión de comportamientos y actitudes lingüísticas tienen mucho que ver con lo que los demás opinen de nosotros. Los 
adolescentes, como comentábamos anteriormente, son muy sensibles ante esta circunstancia. Sentir vergüenza de la variedad utilizada en Murcia es fruto de la preocupación por la imagen que nos creamos de nosotros mismos a través de la opinión de los demás: «Mal. Yo creo que mal, porque en Murcia se habla tan mal que da vergüenza que gente de fuera nos oiga hablar» (T.228). «Creo que en Murcia se habla mal, ya que nos comemos muchas «s». Lo decimos todo a lo bestia y hay muchas palabras malsonantes en este habla. Hay otras regiones que cometen otros fallos en su habla pero quizá el murciano sea uno de los peores vistos ante la sociedad»(T.82). La dependencia heterodiegética en la constitución de actitudes aún esta mas clara en estos otros fragmentos: «Los que son de fuera de Murcia, cuando nos oyen hablar dicen que qué mal hablamos» (T.35), «Creo que en Murcia se habla mal, porque de siempre se ha dicho que los murcianos somos un poco bastos. No vocalizamos bien» (T.71), «Siempre se ha dicho que los murcianos hablamos mal o muy basto» (T.93), «Hablamos mal, porque la gente dice que somos analfabetos»(T.124).

Lo que se dice en TV no sólo parece ser verdad siempre, sino que parece estar bien dicho siempre. La hipnosis es tal que llega a conseguir que la persona pierda su individualidad lingüística para pasar a ser, mas bien, un representante de una determinada comunidad de habla que es comparado con otros representantes de otras comunidades, una visualización de la estereotipia sociosemiótica tradicional (G. Imbert, 1992:19), que puede derivar en autodescrédito de la propia variante lingüística, en inseguridad lingüística y en disfunción entre 10 que se percibe como apropiado y lo que se produce (S. Romaine, 1984: 124): «En general, puede ser que hablemos mal. Muchas veces porque veo programas en los que gente de otra parte de España habla mas fino y mejor» (T.15), «Si hablamos con personas de Murcia nos daremos cuenta de lo mal que se habla, y también podemos verlo en los medios de comunicación, porque cuando sale uno de nuestros representantes comete faltas al hablar» (T.146). El discurso televisivo asigna roles y géneros comunicativos a los distintos acentos regionales, estigmatiza la estética sobre el lenguaje y contribuye a la igualación de actitudes ante la variación lingüística, asunto del que pudimos hablar con anterioridad: «Yo creo que es una ciudad poco calificada en el resto del país, debido a que da una imagen de huerta y de gente inculta» (T.178).

Por lo que respecta al nivel lingüístico en el que se centra la valoración negativa de la variante utilizada en Murcia, digamos que se confirma la afirmación de Michael Stubbs (1987: 68-69) según la cual «La pronunciación o acento es literalmente, desde luego, el aspecto mas superficial y fácilmente observable del lenguaje y, con frecuencia, atrae mas la atención de la que se merece». Dice T.177: «En Murcia se habla mal, porque no utilizamos las «-s» al final de las palabras, ni los «-idos» o «-ados»». Y T.423: «En Murcia, comparando con otras zonas de España, se habla mal, ya que se comen las palabras y no pronuncian bien». Mucho tiene que ver esta circunstancia en lo que se denomina 
valoración estética de los dialectos. El propio M. Stubbs (1987: 27) recuerda que «La noción de que un dialecto es, digamos, estéticamente mas agradable que otro es, como ya hemos visto, una noción aprendida culturalmente que, por lo general, refleja el prestigio social de los hablantes del dialecto, y no propiedades internas del dialecto mismo".

Los temas básicos abordados en esta tendencia a la sobrevaloración del nivel fónico son éstos: 1.-mala pronunciación en general: «En Murcia hablamos mal, porque no pronunciamos bien» (T.12), «En Murcia se habla mal, porque no pronuncian bien las palabras» (T.33), «En Murcia se habla peor que en otros lugares, porque la pronunciación es muy mala» (T.104), «Aunque se diga que hablamos bien, es mentira, en el sentido de pronunciación de palabras» (T.135). 2.- habla basta: "Yo creo que en Murcia se habla mal, porque se habla muy basto» (T.59), «Yo pienso que se habla bastante mal, porque se habla muy bastamente» (T.84), «Dicen que somos bastante bastos hablando» (T.123). 3.mala vocalización: «Se habla mal, porque no se vocaliza bien» (T.10), «Apenas se vocaliza» (T.13), «Somos muy burros, y no sabemos vocalizar la mayoría de murcianos» (T.145), «Creo que en Murcia se habla mal, porque no vocalizamos bien; deberíamos intentar hablar mejor y, sobre todo, vocalizar» (T.217). 4.excesiva abertura vocaliza: «Se habla mal, porque se abren mucho las vocales» (T.201), «Mal, porque algunas vocales se pronuncian muy abiertas» (T.202). 5.omisión de sonidos en general: «Mal, porque la mayoría de la gente habla a medias; o sea, no terminan las palabras que están diciendo» (T.48), «No se habla bien, pues todo el mundo habla con desgana y sin ganas de terminar las palabras» (T.134). 6.- omisión de [s]: «Mal, porque en Murcia no se pronuncia la «S»» (T.38), «Mal, porque muchas veces, cuando hablamos, no pronunciamos la «s»» (T.47), «Mal, porque no se habla con la «s»» (T.57), «En Murcia, como en muchas comunidades de España, se habla con ciertos errores. Yo considero que no pronunciar correctamente las eses a final de palabra o de sílabas es un grave error fonético» (T.118), «Yo creo que hablo regular, porque no soy muy fino, o, sencillamente, porque cuando hablo no pronuncio la «s» al final de palabra» (T.120), «Mal, porque cuando hablamos no pronunciamos las eses; hablamos por hablar» (T.133), «Mal, porque no pronuncio bien las eses; me las como al final de las palabras» (T.136). 7.- omisión de [d]: «En Murcia hablan mal, porque dice «deo» en vez de «dedo»» (T.25), «Se habla mal, porque se habla sin decir las «d»» (T.43), «Hablo mal, porque pronuncio mal las palabras terminadas en «-ado» y en «-ido»»(T.141).

La infravaloración de lo rural y lo antiguo es casi una constante en el esquema metacomunicativo de los adolescentes murcianos que han manifestado una cierta adversión hacia la variedad diatópica de nuestra región. Esta actitud es explicable a partir de la repercusión que lo urbano y lo actual van teniendo en el sistema de valores juvenil y adolescente (Enrique Gervilla, 1993). Ruralidad y antigüedad suelen aparecer como dos caras de una misma moneda: «En 
Murcia se habla mal, porque abundan los ancianos y huertanos, y estas personas son muy incultas» (T.164), «Los que peor hablan son las personas mayores, porque han tenido una peor educación y hablan el lenguaje que había en las calles, que mayoritariamente eran palabras de la huerta» (T.211), «En Murcia se podrían distinguir dos zonas: la gente de la ciudad, que habla casi correctamente, y la gente que vive en el campo, normalmente, suelen ser personas viejas y de alta edad, con lo que la cultura que tienen es muy baja y cometen errores al hablar» (T.90). En ocasiones, incluso se defiende la irrecuperabilidad lingüística de estas personas: «Las personas mayores nunca podrán corregirse» (T.86).

Las asociaciones estético-estilísticas del lenguaje supuestamente producido en ámbitos rurales refuerzan los cimientos de este edificio axiológico:

\section{VALORACIÓN NEGATIVA}

$\begin{array}{cll}\text { TESTIGOS } & \text { ÁMBITOS } & \text { ASOCIACIONES ESTÉTICO-ESTILÍSTICAS } \\ 30 & \text { pueblo } & \text { paletos } \\ 37 & \text { campo-pueblo } & \text { a lo panocho } \\ 76 & \text { campo } & \text { palurdo } \\ 78 & \text { campo } & \text { basto } \\ 88 & \text { campo } & \text { vulgar } \\ 95 & \text { campo } & \text { cerrado } \\ 99 & \text { pueblo } & \text { basto } \\ 110 & \text { huerta } & \text { raro } \\ 111 & \text { campo } & \text { basto } \\ 150 & \text { campo } & \text { bruto } \\ 156 & \text { huerta } & \text { basto } \\ 172 & \text { pueblo } & \text { vulgar } \\ 176 & \text { localidades } & \text { menos culto } \\ 214 & \text { pueblo } & \text { vulgar }\end{array}$

Mención aparte merece el término panocho, cuya diversidad de acepciones, en contexto axiológico negativo, confirma un desconocimiento profundo de la entidad lingüística y extralingüística de este constructo que aparece como muletilla conceptual en el discurso de los adolescentes:

\section{ACEPCIONES DEL TÉRMINO «PANOCHO» ENTRE LOS ADOLESCENTES}

\section{TESTIGOS}

\section{ACEPCIONES DEFENDIDAS EN CONTEXTO NEGATIVO}

lengua originaria de Murcia que se conserva en parte lengua originaria de Murcia que se conserva en parte habla de la huerta murciana lengua originaria de Murcia que se conserva en parte lengua originaria de Murcia que se conserva en parte lengua originaria de Murcia que conservan los viejos lengua originaria de Murcia que conservan los viejos castellano mal hablado-estilo de habla castellano mal hablado-estilo de habla 
castellano mal hablado-estilo de habla castellano mal hablado-estilo de habla castellano mal hablado-estilo de habla lengua originaria de Murcia que conservan los viejos habla de la huerta murciana habla de la huerta murciana

80 habla del campo

81 habla del campo castellano mal hablado-estilo de habla castellano mal hablado-estilo de habla castellano mal hablado-estilo de habla

habla de la huerta

habla de la huerta

habla de la huerta

habla de la huerta

lengua originaria de Murcia que se mantiene en parte lengua originaria de Murcia que se mantiene en parte lengua originaria de Murcia que se mantiene en parte castellano mal hablado-estilo de habla castellano mal hablado-estilo de habla lengua originaria de Murcia que se mantiene en parte

\section{7.- ADVERSIÓN HACIA HÁBITOS SEMIOLINGÜÍSTICOS Y SOCIO- SEMIÓTICOS EXOGRUPALES}

«La gente —dice M.A.K. Halliday (1982: 211)—-reacciona ante el hecho de que otros signifiquen de modo distinto al suyo, y se siente amenazada por ese hecho. No sólo se trata de que tenga aversión a ciertos sonidos, aunque esa sea la forma adoptada superficialmente, sino de cierta aprensión ante ciertas maneras de significación. El problema radica, no en un sistema de vocales distinto, sino en un sistema de valores distinto». En verdad, los adolescentes suelen utilizar sutiles procedimientos de adversión hacia los hábitos comunicativos de quienes, aún siendo de Murcia, no forman parte de la comunidad de referencia del testigo. Nada importa que la valoración de su variante sea positiva puesto que se invierten los términos de valoración: «En Murcia se habla bien porque son de la ciudad y los de la ciudad son muy señoritos» (T.27). Los testigos subsanan su autoexclusión de la categoría de hablantes prestigiosos proponiendo la fortaleza como valor alternativo. Señorito representa a la perfección esta suerte de desprestigio encubierto, como lo cumplen fino, finoli o finolis. Veamos algunos ejemplos que nos recuerdan algún otro reproducido al describir el proceso de adhesión: «Hablamos mal, porque no hablamos finolis» (T.52), «Yo hablo mal, porque soy de pueblo y no me gusta hablar a lo finoli» (T.45), «En Murcia se habla bien, porque los de Murcia capital son muy finos» (T.144), «Hablan bien, porque los de la capital hablan muy finolis» (T.232), «Yo hablo mal, porque soy de pueblo y no me gusta hablar a lo finoli» (T.45), «Los 
murcianos son muy finos comparados con los de Alcantarilla» (T.73), «Se habla regular, porque no se pronuncian las «-s», y no somos tan finos como en Madrid y otras ciudades» (T.75), «Si nos comparamos con Madrid, con los mas finos, pues hablamos mal» (T.182).

\section{8.- ACOMODACIÓN A HÁBITOS SEMIOLINGÜÍSTICOS Y SOCIO- SEMIÓTICOS}

La acomodación comunicativa es uno de los procesos mas estudiados por los investigadores de Psicología social del lenguaje bajo las siglas TAC (Teoría de la Acomodación Comunicativa). Parece evidente, como afirma Michael Stubbs (1987:35), que todo el mundo es multiestilista en tanto que «adapta su estilo de habla a la situación social en que se encuentra». Un interlocutor, en efecto, puede transformar de alguna manera sus hábitos lingüísticos con la intención de atenuar las distancias sociales que le separan de otros. Este tipo de transformación supone una acomodación comunicativa a las normas lingüísticas establecidas por una determinada comunidad y una búsqueda de promoción social. Suzanne Romaine (1984: 84) ya advirtió que es en la adolescencia cuando la persona intensifica su capacidad para dirigir los usos del lenguaje hacia patrones linguístico-discursivos de mayor prestigio social, especialmente en aquellas situaciones marcadas por la formalidad.

El cotejo de las opiniones sobre el lenguaje por parte de los adolescentes con la realidad que ofrece el uso de la comunicación lingüística confirma un alto grado de conciencia lingüística en torno a la necesidad de adaptar el lenguaje a los reclamos del contexto, a la capacidad para realizar esa adaptación y, finalmente, al hecho mismo de adaptarse. Los dos primeros aspectos participan del concepto semiolingüístico de competencia, y el tercero participa, en cambio, del concepto de actuación. Además, las reflexiones de nuestros testigos a propósito de la capacidad de adaptación deben incluirse en el ámbito propio de lo que llamábamos metacompetencia comunicativa, en tanto que la necesidad de adaptación y el hecho mismo de adaptarse lo harían en el ámbito de lo que denominábamos competencia metacomunicativa.

Algunos testigos confiesan ser capaces, en general, de realizar las oportunas acomodaciones linguísticas supuestamente reclamadas por el contexto comunicativo: «Creo que, al menos, me puedo defender hablando, ante situaciones que exijan un cierto grado de nivel cultural en el lenguaje» (T.7), «Cuando estoy en el colegio, hablo vulgar y coloquialmente, pero si adaptarme a las distintas situaciones para trasladar el lenguaje adecuado» (T.87), «Como todos los estudiantes, puedo adaptarme a otras situaciones que requieran hablar de otra manera, con otro lenguaje» (T.162). Los hay que se declaran, por contra, incapaces de realizar tales acomodaciones: «No si expresarme bien ante perso- 
nas bien habladas» (T.33), «Creo que hablo mal, no por no saber decir palabras, sino por no saber expresarme bien en cualquier situación» (T.58), «La gente joven dice mas tacos que otra cosa, y a la hora de ir a algún sitio, no sabemos qué lenguaje utilizar» (T.139). Por lo que se refiere a la capacidad de acomodación, además, existen referencias a la inevitable bidireccionalidad de toda atenuación de las distancias comunicativas: la acomodación ascendente y la acomodación descendente; es decir, convergir a través del lenguaje con grupos o personas consideradas superiores según los patrones de jerarquización social vigentes en determinados colectivos, o bien pergeñar estrategias para convergir mediante los usos comunicativos con grupos o personas consideradas inferiores en la escala de valoración social vigente en determinados colectivos: «Mi padre habla bastante bien; es capaz de hablar en la huerta la lengua «huertana», y en la ciudad hablar bien» (T.211). La televisión no es ajena a este tipo de procedimientos: «Pienso que la televisión deteriora mucho la lengua, sobre todo las telenovelas, ya que las hacen para que el mas tonto las entienda también» (T.115).

Cambiemos, ahora, nuestra perspectiva de análisis para pasar al ámbito de la actuación lingüístico-comunicativa. He aquí algunos testimonios que nos informan de los tipos de interlocutores y de los contextos considerados asimétricos por los adolescentes y de los acomodadores lingüísticos utilizados para llevar a cabo el aparente acercamiento interlocutivo:

\section{CONTEXTOS, INTERLOCUTORES Y ACOMODADORES LINGÜÍSTICOS}

$\begin{array}{ll}\text { TESTIGOS } & \text { CONTEXTOS-INTERLs. } \\ \text { T.2 } & \text { padres-profesores } \\ \text { T.15 } & \text { ni familia ni amigos } \\ \text { T.17 } & \text { en clase } \\ \text { T.23 } & \text { adultos-profesores-Murcia cap. } \\ \text { T.49 } & \text { familia } \\ \text { T.53 } & \text { alguien importante } \\ \text { T.79 } & \text { personas importantes } \\ \text { T.89 } & \text { personas mayores } \\ \text { T.91 } & \text { personas mayores } \\ \text { T.92 } & \text { gente mayor } \\ \text { T.93 } & \text { padres } \\ \text { T.98 } & \text { profesores-persona mayor } \\ \text { T.100 } & \text { amigos de mis padres } \\ \text { T.105 } & \text { persona mayor } \\ \text { T.114 } & \text { escuela } \\ \text { T.118 } & \text { colegio } \\ \text { T.128 } & \text { personas no-conocidas } \\ \text { T.153 } & \text { personas que merecen respeto } \\ \text { T.172 } & \text { persona mayor } \\ \text { T.177 } & \text { sitio de mas clase } \\ \text { T.180 } & \text { personas que no conozco } \\ \text { T.187 } & \text { personas menos conocidas } \\ \text { T.192 } & \text { persona mayor }\end{array}$

\author{
ACOMODADORES \\ utilizar vocabulario distinto \\ pronunciar las eses \\ utilizar vocabulario distinto \\ Hablar bien \\ utilizar vocabulario distinto \\ hablar bien \\ dar buena imagen \\ utilizar lenguaje culto \\ no hablar de ciertos temas \\ hablar con educación \\ utilizar vocabulario distinto \\ hablar con corrección \\ hablar con educación \\ hablar con respeto \\ hablar mejor \\ hablar mejor \\ hablar bien \\ hablar con educación \\ no decir tacos \\ utilizar vocabulario distinto \\ pensar lo que se dice \\ hablar con corrección \\ hablar con educación
}


T. 193

T. 195

T. 209

T.213

T.218 no amigos

casa

ámbito no juvenil

familia-en clase

persona mayor-persona culta hablar bien

hablar bien

hablar mejor

hablar mejor

hablar con corrección

Los hablantes necesitan información para generar esquemas de interacción discursiva, pero también ofrecen, a su vez, información que garantice la reciprocidad del proceso; ésta es una de las funciones básicas de las acomodaciones comunicativas, especialmente en aquellos casos en los que se interaccione con desconocidos o en contextos marcados por un alto grado de formalidad y, por tanto, de previsibilidad. Además, si uno de los referentes psicológicos del establecimiento de prototipos era la incertidumbre, uno de sus referentes sociológicos (de socialización) es, sin duda, la idealización, tal y como es concebida por el profesor norteamericano Erving Goffman (1987: 59): «El que actúa produce a menudo en los miembros de su auditorio la creencia de que está relacionado con ellos de un modo mas ideal de lo que en realidad lo está». La fachada verbal (Goffman, 1987: 35 y 169) tiene mucho que decir en ese aparentar mayor convergencia de la realmente existente entre los intervinientes en el proceso comunicativo. T.79 es el prototipo de persona que reconoce la proximidad entre el modo de hablar, la apariencia y la interacción asimétrica ascendente. Confiesa que habla mejor ante personas importantes para dar buena imagen. Los adolescentes, en general, se inclinan por la pronunciación, el vocabulario y el estilo discursivo para dar cuerpo definitivo a esa superficie. T.15 ni siquiera se refiere a la pronunciación o al acento murciano en general, sino que invierte los términos de una tendencia típica de la variante meridional (no pronunciar las eses finales de sílaba) como prueba de acomodación en interacciones con personas que no pertenecen a la familia ni al círculo habitual de amistades (convergencia acentual).

El segundo procedimiento de acomodación ascendente específica corresponde a la variación de aspectos léxicos. El saber enciclopédico goza de gran consideración entre los adolescentes. Cinco testigos confiesan alternar su vocabulario para adaptarse a interacciones con padres y profesores, fundamentalmente. No decir tacos (T.172) también participa de este mismo nivel de acomodación y encuentra su réplica discursiva en los temas considerados tabúes cuando se habla con personas mayores; esto es, cuando la asimetría se sustenta en diferencias generacionales (T.91). La conocida máxima socrática «Háblame para que te vea» expresa con claridad cómo el lenguaje refleja, en gran medida, no sólo la personalidad del que habla, sino también sus modales, su educación, su conocimiento de las normas de urbanidad y cortesía. Por todo esto, la adaptación del estilo de habla (hablar con educación, hablar con corrección y hablar con respeto) en interacciones con personas mayores, poco conocidas, merecedoras 
de respeto o cultas es considerada por ocho adolescentes como el sustento fundamental de sus acomodaciones.

Mediante la comunicación aprendemos a quién admirar. Esta afirmación. recogida por Kathleen $\mathrm{K}$. Reardon en su libro La persuasión en la comunicación. Teoría y contexto $(1983: 28)$, nos viene a recordar que el reconocimiento social, el triunfo, va asociado a modelos comunicativos. Su adquisición es concebida como condición sine qua non para quienes luchan no sólo por admirar, sino también por llegar, en algún momento, a ser objeto de admiración. John T. Cacioppo y Richard E. Petty (1982: 189-190) han analizado, justamente, la interrelación de variables linguiísticas, actitudes y persuasión, y concluyen, entre otras cosas, que existe una función utilitaria e instrumental de las actitudes, mediante la cual el lenguaje sirve para crear un contexto actitudinal propicio a la consecución de recompensas sociales. Algunos adolescentes son muy sensibles a la relación entre lenguaje y consecución o desempeño de un trabajo: «Mis padres hablan bien porque trabajan en Murcia capital» (T.38), «El habla es muy importante ya que para cualquier trabajo se necesita una comunicación clara, tanto en el extranjero como en nuestro propio país» (T.58), «El hablar bien socialmente es fundamental y necesario, ya que no se encuentra hoy día ningún trabajo a no ser que estás bien preparado y puedas entablar una buena comunicación» (T.60), «En Murcia capital las personas tienen un habla mas culta y tienen trabajos muy importantes en los que se necesita tener un buen vocabulario» (T.143), «Mi padre tiene estudios y trabaja en un sitio que tienes que cuidar mucho tu lenguaje, porque tiene que estar todo el día trabajando y hablando con mucha gente, y él mismo esta corrigiendo sus errores» (T.161), «Mis padres tienen trabajos en los que hablar bien, con propiedad, juega un papel muy importante» (T.219). Igualar o, en su caso, superar el listón sociolaboral que muestra la familia es determinante en la instrumentalización social del lenguaje: «Mis padres me han enseñado a hablar mejor que ellos, para llegar mas lejos de donde están ellos» (T.175).

\section{9.-ASIMILACIÓN DE HABITOS SEMIOLINGÜÍSTICOS Y SOCIO- SEMIÓTICOS}

Con frecuencia, el grupo dominante promociona sus actuaciones linguiísticas como, a veces, modelos para quienes desean avanzar socialmente (E. B. Ryan H. Giles - R. J. Sebastián, 1982: 1). La acomodación lingüística, como la persuasión verbal, suponen negociación desigual. El gasto de una de las instancias locutivas es muy superior al de la otra, ya que para la primera supone, en cierto sentido, una desnaturalización linguística, una desautomatización que, llevada con excesivo celo, pudiera acabar en hiperconvergencia o hiperacomodación (H. Giles- N. Coupland, 1991: 68). En ocasiones, los iguales pueden 
interpretar como asimilación lo que en contextos asimétricos constituiría mera convergencia acomodaticia: «Un dato curioso es que cuando hablas correctamente, la gente te dice: "qué fino que se ha puesto, qué finolis, etc"» (T.106), «Yo he visto gente que va a comprarse ropa o algo a Murcia capital y las eses les sobran por todas partes» (T.113), «Si hablas bien te miran como a un bicho raro $y$ te preguntan si eres de fuera» (T.148).

\section{0.- INTER VENCIONES TEÓRICO-DIDÁCTICAS EN LOS PROCESOS DE VALORACIÓN LINGÜÍSTICA}

Estamos de acuerdo con el profesor José-M $M^{a}$ Jiménez Cano (1986: 53) cuando afirma que «La didáctica de la lengua tiene que decidir si plantea la enseñanza linguiística desde una opción invariante, desde una norma ejemplar desde la que se discierne la idoneidad (corrección) de los diferentes usos, o si se abre a una opción variante, presentando diferentes normas que se describen y explican, pero que, en principio, no se juzgan desde un sólo parámetro». Sobre esta alternativa actitudinal deben pronunciarse, inicialmente, tanto quienes tienen capacidad decisoria en la macroestructura educativa, como quienes la tienen o pudieran tenerla en la microestructura educativa. El proceso de reforma educativa que se esta llevando a cabo en nuestro país parece haber apostado por la segunda opción, al revitalizar los asuntos relativos a actitudes ante las variedades geográficas del español y ante la contribución del entorno en el desarrollo comunicativo del adolescente ${ }^{6}$. En el Diseño Curricular Base de Lengua y Literatura durante la ESO se realizaba la siguiente consideración: «La enseñanza y el aprendizaje de la lengua y de la literatura están estrechamente vinculados a la realidad circundante, por lo que debe concederse especial atención al contexto cultural y linguiístico (lenguas y variantes idiomáticas) de la localidad, región o nacionalidad de los alumnos, impulsando su interés por el mismo y fomentando su valoración positiva». En este mismo documento, se reconoce que «La selección de los contenidos debe atender no sólo a la valoración de los niveles cultos de la lengua, sino también a las variantes idiomáticas y a los registros o usos marcados por la procedencia social de los alumnos, que serán analizados y modificados cuando resulte necesario, pero siempre con actitud respetuosa». Y entre los objetivos generales se menciona este otro: «Reconocer y respetar las peculiaridades de las diferentes lenguas del Estado español, así como las variantes dialectales del castellano o, en su caso, de la lengua propia de la Comunidad Autónoma, como manifestaciones de una pluralidad cultural y lingüística enriquecedora».

Cfr. «Investigación sobre el uso del entorno», AA.VV., en Cuadernos de Pedagogía n:196, octubre de 1991, Barcelona. 
Las propuestas curriculares ligadas a las Administraciones Autonómicas defienden patrones similares. Detengámonos, por ejemplo, en el documento preparado por Felipe Zayas para la Generalitat de la Comunidad Valenciana, bajo el título Propuesta curricular de lengua castellana. Enseñanza Secundaria Obligatoria. Dice Felipe Zayas (1987: 6): «Desde este interés por los usos y no sólo por el sistema, por las variedades y no sólo por lo regular, es importante que en la clase de lengua se desarrollen actitudes positivas hacia la diversidad de lenguas, dialectos y registros y se arranquen estereotipos y prejuicios». Entre esos estereotipos, nos interesa mencionar para el tema que tratamos los siguientes (1987: 17): «Hay lenguas mas evolucionadas que otras y mas adecuadas para la transmisión del pensamiento y de las formas culturales», «Los dialectos de una lengua son formas de hablar incorrectas, descuidadas y poco elegantes, propias de gente sin instrucción», «La gente que no habla según la norma culta es menos inteligente, posee menos cualidades intelectuales». Estos prejuicios pueden afectar tanto al estilo cognitivo de alumnos como de profesores, e impedir el normal desarrollo del proceso educativo (R. A. Hudson, 1982: 225).

Los profesores de lengua, en casi todos los niveles educativos, se encuentran con la didáctica sin haber tenido tiempo para reflexionar sobre ella? Hoy por hoy, son pocos los profesores de ESO responsables del área de lengua española que disfrutan de una formación sólida a propósito del desarrollo socio-cognitivo y metacomunicativo de los adolescentes, a pesar de su importancia: «Creemos de todo punto necesario que los educadores conozcan esta etapa evolutiva del hombre desde una perspectiva psicosocial, ya que son precisamente las variables psicosociales las que, mas que ninguna otra, influirán en la formación del adolescente y en su comportamiento social» (A. Ovejero, 1988: 45). Otra cosa es que puedan tener nociones intuitivas, fruto, por lo normal, de la propia experiencia laboral, o que puedan adecuarse a estas etapas de desarrollo sin saberlo, poniendo en practica, únicamente, los contenidos y ejercicios tal y como vienen ordenados en los distintos libros de texto, los cuales - dicho sea de paso- carecen, en muchos casos, de prólogos o introducciones que adviertan sobre la búsqueda y consecución. o no, de puentes de unión entre los distintos campos de conocimiento.

Por otra parte, los planes de estudio en el ámbito fillológico han marginado, con frecuencia, la preparación teórico-práctica de los futuros profesores de lengua en aspectos sociolingüísticos, tan importantes en el incompleto desarrollo comunicativo y social del adolescente: «Aunque un niño haya adquirido lo esencial de un sistema gramatical amplio y complejo a la edad en la que

Poca rentabilidad cabe atribuir, además, a los cursos de adaptación del profesorado con que culminan los estudiantes de determinadas carreras su supuesta preparación para cjercer la docencia y que, tal y como están planteados en la actualidad, pasan por ser, en el mejor de los casos, una benévola (en tanto que bien intencionada) pero insatisfactoria etapa de transición, y más teniendoen cuenta que están edificadas habitualmente sobre la errónea creencia de que quienes mejor pueden hablar de los contornos psicosociales y psicopedagógicos de una asignatura son los especialistas eii los contenidos de dicha asignatura. 
empieza a ir al colegio (cuatro o cinco años), seguirá adquiriendo el sistema sociolingüístico hasta bien entrado en la adolescencia o incluso mas tarde» (M. Stubbs, 1987: 35). La urgente formación interdisciplinar debe ir pareja a la reflexión permanente por parte del profesorado sobre los progresos de su propia disciplina. El conocimiento de la teoría acaba transplantándose de una u otra forma a la calidad de la praxis educativa .

Al margen de generalizaciones injustas, reconocemos que quizás sean estas carencias las que justifiquen los poco apropiados comportamientos que, a veces, se producen en el aula, cuando el profesor de lengua discierne sobre su misión básica, o simplemente la aplica: «Sería equivocado suponer que todos los maestros caen en esta trampa, pero tan equivocado sería también el ignorar la gran cantidad de maestros que creen que una de sus principales funciones consiste en indicar a los niños que hablan dialectos o acentos no estandares que su habla es imperfecta, con la esperanza de que corregirán sus hábitos» (R. A. Hudson, 1982: 221). El profesor de lengua, mas bien, «debería estar preparado para reconocer tanto sus propias actitudes linguísticas populares como las de otras personas e, idealmente, para explorar dichas actitudes, con la participación de los alumnos. La propia experiencia de los alumnos les dirá que el lenguaje es uno de los muchos aspectos del comportamiento humano que los demás juzgan «bueno» o «malo»; se les puede alentar a tratar de encontrar por qué ocurre así y el maestro les puede guiar hacia la comprensión que les permita ver a través y mas allá de esos juicios (...). Esto trae a colación las cuestiones del dialecto y del acento, de lo estandar y lo no estandar (...). Si la lengua estandar difiere de nuestra lengua materna no tiramos nuestra lengua materna; hay funciones del lenguaje para las que la una es apropiada y no la otra. A decir verdad, aprender inglés estandar es cuestión de aprender nuevos registros mas que de aprender un nuevo dialecto». Estas reflexiones de Michael A. K. Halliday (1982: 303) tocan temas fundamentales para el estudio de la variación lingüística en el marco educativo. El profesor actúa no sólo como modelo lingüístico, sino también como modelo de valoración personal, dado que sus consideraciones revierten a la estructura de pensamiento de los adolescentes (A. Ovejero, 1988: 104). Por eso, conviene que ejerza la autocrítica y que reconozca, cuando así sea, que las características dialectales de los discentes le hacen pergeñar expectativas injustas y prejuiciosas: «Con frecuencia los maestros basan su juicio inicial sobre un niño y sus expectativas acerca de su rendimiento en gran medida en su acento; lo cual es sumamente dañino, dado que un niño - como un adulto- suele comportarse como se espera que lo haga» (M.A.K. Halliday, 1982: 303). Igualmente, conviene que depure, de una vez por todas, posibles confusiones entre diferencia lingüística y deficiencia comunicativa: «La tendencia de los maestros y los terapeutas de lenguas a confundir las diferencias dialectales con los desórdenes del lenguaje, y a considerar las formas no estandar como defectos del habla sigue siendo, sin embargo, un problema 
primordial en las actitudes socialmente condicionadas» (M.A.K. Halliday, 1982: 125). La actitud de respeto hacia los compañeros con disfunciones acabaría calando en las mentes de los adolescentes a partir de esclarecimientos conceptuales como éste y de los consiguientes comportamientos antidiscriminatorios con respecto a la variación lingüística en general $^{8}$.

Siguiendo las propuestas del aprendizaje significativo, la consolidación de actitudes equilibradas o el cambio de actitudes extremas debieran, por lógica, partir de una sistematización previa de las actitudes ya interiorizadas por los alumnos de Educación Secundaria Obligatoria: «El docente debe comprobar en qué situación se encuentra cada alumno y qué contenidos tiene ya interiorizados» (DCB de Lengua y Literatura) . Estas actividades de medición, al estilo de la realizada por nosotros en la primera parte de este trabajo, ayudan a conformar un prototipo lingüístico-actitudinal rentable si aceptamos propuestas genéricas como las del profesor Juan A. García Madruga (1991: 49-50): «Podríamos resaltar el papel crucial que los conocimientos previos, los esquemas que ya posee el sujeto, tienen en la determinación de lo que los alumnos pueden aprender y la necesidad de proporcionar y activar las estructuras cognoscitivas de nivel superior adecuadas en las que puedan ser integrados los nuevos conocimientos (...). Desde un punto de vista evolutivo, además de resaltar la importancia del conocimiento en el desarrollo, los estudios recientes sobre la adquisición de conceptos y categorías resaltan el que se realiza a partir de la construcción de estructuras prototípicas, semejantes a los esquemas, y no mediante conceptos definidos por atributos organizados lógicamente».

Promover la reflexión de los alumnos sobre muestras de diversidad dialectal y diversidad de registros pasa por eliminar, de entrada, las actitudes pasivas del discurso y del comportamiento de los adolescentes. La información atinada atenuaría la inhibición que, muy probablemente, radique en las valoraciones negativas que (pudimos constatarlo) los habitantes hacen de su habla: «En cualquier caso es básico no perder de vista que en general los hablantes

\footnotetext{
No sería difícil extraer conclusiones sobre la importancia de las actitudes de los agentes educativos hacia alumnos con desórdenes, en general, para conseguir su integración; es un problema, además, de plena actualidad: «Veamos la importancia de las actitudes para la solución adecuada de ciertos problemas educativos que los responsables públicos desean resolver y cuya resolución parece ser difícil si no los abordamos desde la perspectiva correcta. Si atendemos, por ejemplo, a que en el año 1985 se ha promulgado la normativa por parte del Ministerio de Educación y Ciencia Español sobre la integración de los niños diferentes, o con deficiencias, en los centros educativos ordinarios, nos encontramos que es imprescindibie investigar y, en su caso, cambiar las actitudes que hacia los niños tienen sus previsibles compañeros de clase, sus potenciales maestros y las familias tanto de esos niños como las de aquellos que serán sus iguales. Si esto no se realiza así, sino que solamente se impone por decreto, posiblemente los resultados no serán halagüeños. Una medida de política educativa de tanta trascendencia puede convertirse en un fracaso si las actitudes de la población implicada en el tema no son las adecuadas o no se ha procurado que lo sean» (J. Escamez - P. Ortega, 1993:15).
} 
dialectales tienen una acusada sensibilidad negativa hacia su propia variedad y que no estaría de mas informarles sobre la verdadera naturaleza de ésta, lo cual no equivale a predicar su idoneidad para todos los usos» (J. Borrego Nieto, 1990: 152). Entre los contenidos de esa información los agentes educativos deben incluir la rentabilidad interlocutiva del dominio de variedades lingüísticas, ai margen de criterios de prestigio o calidad (F. Zayas, 1987: 17). En este orden de asuntos, para la consolidación de la competencia metacomunicativa de los adolescentes, sería plausible, a nuestro entender, intensificar la asociación de la idea de acomodación semiótica a la noción sociolingüística de registro, «que caracteriza las variantes de uso lingüístico. Estas dependen de la naturaleza de las relaciones que mantienen los interlocutores, de sus intenciones, de los temas abordados, del grado de familiaridad o formalidad escogido. Este concepto esta ligado a los locutores y a las variantes de habla. Así, se dirá que cada locutor dispone de varios registros habituales o preferenciales en el uso que hace de su lengua. Llevados al ámbito escolar, estos conceptos nos descubren que no existe una única lengua oral sino que como en el caso de la lengua escrita ella dispone de una gran variedad de realizaciones y que la verdadera competencia de comunicación reside en saberse adaptar lo mejor posible a las variaciones que requiere la situación» (C.R. García Fernández, 1987: 30). Que profesores y alumnos ejercen por doquier esta capacidad es una afirmación elemental, pero quizás no esté de mas reiterarla de vez en cuando y aprovecharla con mayor asiduidad en el fomento de la diversificación de interacciones en el aula: «Un profesor puede tender a pensar en el lenguaje de un niño de una forma estereotipada, como si el niño fuese un hablante con una variedad única. Pero es típico que el profesor vea al niño nada mas que en una gama reducida de situaciones sociales en las aulas, con lo que puede olvidar que el niño también controla otras variantes linguiísticas. En otras palabras, muchos profesores no son conscientes de que todas las comunidades lingüísticas emplean gamas de distintas variantes lingǘrsticas en distintos contextos sociales; sin embargo, este hecho sociolingüístico es elemental. Por el contrario, muchos profesores mantienen la creencia de que sólo hay una lengua «óptima» para todos los propósitos, y que ésta es la única lengua adecuada en la clase» (M. Stubbs, 1987: 31).

No pueden caer en saco roto las palabras de advertencia de personas tan prestigiosas como el profesor Anastasio Ovejero sobre la importancia que en el proceso de socialización de niños y adolescentes ha adquirido la televisión: «Cada vez mas niños y adolescentes emplean cada vez mas tiempo ante la televisión y no con sus padres, ni con otros adultos, ni siquiera con otros compañeros: sólo la TV absorbe su tiempo, hasta convertirse en el principal instrumento de socialización» (1988: 273). Este es uno de los motivos por los que el DCB de Lengua y Literatura incluye entre los objetivos actitudinales la superación de lo que podríamos llamar el «voyeurismo» frente a los medios de comunicación: «Recepción activa y actitud crítica ante los mensajes de los 
distintos medios de comunicación» (p. 394)9. Los alumnos deben estudiar, bajo la dirección de su profesor de lengua, la presencia de dialectos y acentos no estandares en programas y franjas horarias de televisión, y preguntarse por las causas que explicarían su baja incidencia en informativos y su aprovechamiento en todo tipo de comedias y programas de humor ${ }^{10}$ (J. Mallory Wober, 1990: 571572). Una sencilla actividad podría consistir en preguntarse, igualmente, porqué, por ejemplo, Curro Jiménez, siendo andaluz de pura cepa y bandido, hablaba según modelos lingüísticos claramente estandares (J. Borrego Nieto, 1990: 152). Tal vez porque se nos presentaba como un héroe. Ejercicios como éste, a la par que atractivos para los alumnos, harían de la oralidad textual un concepto mas relevante de lo que lo ha sido hasta ahora, y de los medios audiovisuales objetivos cercanos al mundo de la escuela.

Curiosamente, hemos observado que los adolescentes encuestados, cuando mencionan la TV, lo hacen para criticar sus supuestas bondades lingüísticocomunicativas, $y$, sin embargo, sabemos que progresa el número de horas frente a la caja (que a-)tonta. La disfunción entre valoración y actuación es evidente, aunque hay que aprovechar, al menos, esa actitud discursivamente crítica.

\section{1.-A MODO DE CONCLUSIÓN}

El profesor de Lengua debe conocer las propuestas educativas actuales en materia de actitudes ante la diversidad linguística, y pronunciarse sobre ellas. Debe ser consciente, de igual manera, de la posible existencia en su propia estructura de pensamiento de prejuicios derivados de sus actitudes hacia el lenguaje de los alumnos, prejuicios que, por lo normal, cuentan con alta probabilidad de transmisión al prototipo actitudinal del mismo adolescente.

Hay que sacar rentabilidad a las actividades de medición de los contenidos interiorizados por los adolescentes. Habrá de analizarse las actitudes de los

9 La Universidad de Yale (USA) creó en 1975 un Centro para la Investigación de la Televisión y la Familia con la intención de analizar el impacto de la televisión en el desarrollo sociocognitivo de niños, adolescentes y jóvenes. El año pasado elaboró un currículo enviado a numerosos centros educativos del país, cuyo objetivo fundamental era ayudar a los adolescentes a criticar y analizar lo que ven en TV. Mas del 50\% de los jóvenes norteamericanos entre 14-15 años disponen de su televisión propia y se fían mas de lo que éste les dice que de lo que les puede decir su padre o su madre. (El País. Educación n:491, martes, 4 de mayo de 1993). Se echan en falta centros e iniciativas de esta naturaleza en nuestro país.

10) En uno de los últimos programas de Al Ataque, de Antena 3, Alfonso Arús y sus colaboradores se mofaban del lenguaje de un sindicalista murciano, y en otros de los últimos programas de Viéndonos, los humoristas Martes y 13 improvisaban una zafia imitación del acento murciano. Este mismo año, el Ministerio de Educación y Ciencia, junto con representantes autorizados de las cadenas españolas de televisión, firmaban un acuerdo sobre un futuro código deontológico para la protección de la juventud y de la información en temas como la violencia, el sexo, el consumo o el lenguaje. Suponemos que en este último asunto no se contemplaría el rechazo de actitudes discriminatorias hacia las variedades dialectales. (Cfr. diario La Verdad, 27 de abril de 1993). 
alumnos en el marco de su competencia comunicativa y metacomunicativa. Ciertamente, el desarrollo de las «habilidades metacomunicativas», en general, «supone una toma de conciencia de los procesos implicados en el manejo de lenguaje» (A. Medina Padilla, 1989: 74). Dado que el profesor tiene entre sus objetivos el apuntalar la competencia sociolingüística del discente, estas actividades les resultaran de gran interés, si bien no hay que ocultar que, en parte, supone una apuesta decidida por la implicación del profesor en la investigación sobre la interacción didáctica, concepto muy en boga en los últimos años (Renzo Titone, 1986 y Sara Delamont, 1984).

Es urgente la intervención en casos de inseguridad linguiística puesto que peligran los marcos analíticos del adolescente, que pueden quedar asentados en la duda sistemática y en la ausencia de referentes inmediatos valiosos desde el punto de vista del lenguaje. Respetar la diversidad comienza por respetarse a sí mismo como representante de lo diverso. Todas las propuestas de revitalización de las variantes no estandares propias del entorno educativo del discente serían de gran ayuda. Ya existen iniciativas en este sentido, por ejemplo en Andalucía (Jerónimo de las Heras Borrero, 1989). La diferencia lingüística no puede interpretarse en términos de deficiencia linguística. Por eso, conviene potenciar los discursos que defiendan, en principio, la adecuación comunicativa y que promuevan la desaparición de la tendencia a la homogeneización actitudinal tal y como ha sido comentada en este trabajo.

La diversidad lingüística debe ser objeto de discusión racional en clase. La información y la racionalización aseguran, de alguna manera, la atenuación de actitudes extremas de adhesión o adversión, cuya presencia en el discurso de algunos adolescentes murcianos es evidente. Igualmente, servirán para ayudar al alumno a eliminar actitudes pasivas y para alejarse del aprovechamiento acrítico de conceptos aprehendidos desde parámetros deformados; pensemos, por ejemplo, en el término panocho. En este sentido, es lamentable la desconsideración mostrada por algunos alumnos hacia todo aquello que proceda del lenguaje de la huerta o del lenguaje manejado por los ancianos.

El sentimiento de identificación grupal no tiene que ser directamente proporcional al monolitismo lingüístico. A partir de la noción de registro y de lengua funcional la acomodación comunicativa puede estudiarse como una herramienta útil para abordar la complejidad de los contextos comuncativos, al margen de falsas interpretaciones de asimilación sociocultural.

En clase de lengua no pueden marginarse los textos orales en los que aparezcan características del habla local. Al contrario, debiera promoverse su uso y su análisis. El aprendizaje cooperativo (Anastasio Ovejero Bernal, 1990) contribuiría a la generación o, en su caso, consolidación de actitudes favorables hacia la diversidad lingüística.

Una vez reconocida la responsabilidad parcial de los medios audiovisuales en la conexión entre patrones comunicativos y de prestigio (o desprestigio) 
social, en la pasividad actitudinal del adolescente y en la creación de obstáculos para la afirmación de valores propios (M. Ventura Limosner, 1993: 24), se impone la creación de técnicas y ejercicios tendentes a la interpretación crítica de los mensajes televisivos en aspectos de diversidad lingüística. Hay que desautomatizar a los "adolescentes teledependientes»" 0 tendentes a la dependencia. El uso del vídeo, con la grabación y el análisis, por ejemplo, de entrevistas a inmigrantes (J. Ferris, 1989: 31), contribuiría a la reflexión pausada sobre las conexiones entre actitudes y lenguaje.

\section{ANEXO. CARACTERIZACIÓN DE LOS TESTIGOS}

\begin{tabular}{|c|c|c|c|c|c|c|c|}
\hline TEST & EDAI & $\mathrm{XO}(*)$ & $\begin{array}{l}\text { LOCALIDAD } \\
\text { RESIDENCIA }\end{array}$ & TEST & DAI & $\mathrm{XO}(*)$ & $\begin{array}{l}\text { LOCALIDAD } \\
\text { RESIDENCIA }\end{array}$ \\
\hline 1 & 16 & M & Murcia & 34 & 15 & $\mathrm{H}$ & E1 Raal \\
\hline 2 & 15 & $\mathrm{H}$ & Puente Tocinos & 35 & 16 & $\mathrm{H}$ & El Raal \\
\hline 3 & 16 & $\mathrm{H}$ & EI Raal & 36 & 12 & $\mathrm{H}$ & El Raal \\
\hline 4 & 15 & $\mathrm{H}$ & El Raal & 37 & 12 & $\mathrm{H}$ & El Raal \\
\hline 5 & 16 & M & Puente Tocinos & 38 & 14 & $\mathrm{H}$ & El Raal \\
\hline 6 & 16 & M & Puente Tocinos & 39 & 14 & M & El Raal \\
\hline 7 & 16 & M & Murcia & 40 & 13 & $\mathrm{M}$ & El Raal \\
\hline 8 & 15 & M & Puente Tocinos & 41 & 12 & $\mathrm{H}$ & El Raal \\
\hline 9 & 15 & M & Murcia & 42 & 14 & $\mathrm{H}$ & El Raal \\
\hline 10 & 16 & M & Puente Tocinos & 43 & 12 & $\mathrm{H}$ & El Raal \\
\hline 11 & 15 & $\mathrm{H}$ & Puente Tocinos & 44 & 13 & M & El Raal \\
\hline 12 & 15 & M & Puente Tocinos & 45 & 14 & M & El Raal \\
\hline 13 & 15 & M & Puente Tocinos & 46 & 14 & $\mathrm{H}$ & El Raal \\
\hline 14 & 15 & M & Murcia & 47 & 14 & M & Alcantarilla \\
\hline 15 & 16 & M & Murcia & 48 & 13 & M & Alcantarilla \\
\hline 16 & 16 & $\mathrm{H}$ & Murcia & 49 & 13 & $\mathrm{M}$ & Alcantarilla \\
\hline 17 & 15 & $\mathrm{H}$ & Puente Tocinos & 50 & 14 & $\mathbf{M}$ & Alcantarilla \\
\hline 18 & 15 & $\mathrm{H}$ & Murcia & 51 & 13 & M & Alcantarilla \\
\hline 19 & 16 & $\mathrm{H}$ & Murcia & 52 & 13 & M & Alcantarilla \\
\hline 20 & 16 & $\mathrm{H}$ & Beniajan & 53 & 12 & M & Alcantarilla \\
\hline 21 & 12 & M & Sangonera la Verde & 54 & 12 & M & Aicantarilla \\
\hline 22 & 12 & M & Sangonera la Verde & 55 & 13 & M & Alcantarilla \\
\hline 23 & 12 & $\mathrm{H}$ & Sangonera la Verde & 56 & 13 & $\mathrm{M}$ & Alcantarilla \\
\hline 24 & 12 & M & Sangonera la Verde & 57 & 13 & $\mathrm{H}$ & Alcantarilla \\
\hline 25 & 13 & $\mathrm{H}$ & Sangonera la Verde & 58 & 15 & $\mathrm{M}$ & Alcantarilla \\
\hline 26 & 14 & $\mathrm{H}$ & Sangonera la Verde & 59 & 15 & M & Alcantarilla \\
\hline 27 & 13 & $\mathrm{M}$ & El Raal & 60 & 15 & M & Alcantarilla \\
\hline 28 & 13 & M & El Raal & 61 & 15 & $\mathrm{M}$ & Alcantarilla \\
\hline 29 & 13 & M & El Raal & 62 & 16 & $\mathrm{H}$ & Alcantarilla \\
\hline 30 & 13 & $\mathrm{M}$ & El Raal & 63 & 15 & $\mathrm{H}$ & Alcantarilla \\
\hline 31 & 14 & $\mathrm{M}$ & EI Raal & 64 & 14 & $\mathrm{M}$ & Alcantarilla \\
\hline 32 & 14 & M & El Raal & 65 & 15 & $\mathrm{H}$ & Alcantarilla \\
\hline 33 & 14 & $\mathrm{M}$ & El Raal & 66 & 14 & $\mathrm{H}$ & Alcantarilla \\
\hline
\end{tabular}

11 Cfr. El País. Educación n:32, martes, 28 de diciembre de 1982, y Cuadernos de Pedagogía $\mathrm{n}: 137$, mayo de 1986 . 


\section{TEST. EDAD SEXO (*) LOCALIDAD RESIDENCIA}

\begin{tabular}{|c|c|c|c|}
\hline 67 & 15 & $\mathrm{H}$ & Alcantarilla \\
\hline 68 & 15 & $\mathrm{H}$ & Alcantarilla \\
\hline 69 & 14 & $\mathrm{H}$ & Alcantarilla \\
\hline 70 & 15 & $\mathrm{M}$ & Alcantarilla \\
\hline 71 & 16 & $\mathrm{M}$ & Alcantarilla \\
\hline 72 & 14 & $\mathrm{M}$ & Alcantarilla \\
\hline 73 & 14 & $\mathrm{M}$ & Alcantarilla \\
\hline 74 & 15 & $\mathrm{M}$ & Alcantarilla \\
\hline 75 & 16 & $\mathrm{H}$ & Alcantarill \\
\hline 76 & 16 & $\mathrm{H}$ & Cartagena \\
\hline 77 & 14 & $\mathrm{H}$ & Cartagena \\
\hline 78 & 14 & $\mathrm{M}$ & Cartagena \\
\hline 79 & 14 & $\mathrm{M}$ & Cartagena \\
\hline 80 & 15 & $\mathrm{M}$ & Cartagena \\
\hline 81 & 14 & $\mathrm{M}$ & Cartagena \\
\hline 82 & 15 & $\mathrm{M}$ & Cartagena \\
\hline 83 & 14 & $\mathrm{M}$ & Cartagena \\
\hline 84 & 14 & $\mathrm{H}$ & Cartagena \\
\hline 85 & 14 & $\mathrm{H}$ & Cartagena \\
\hline 86 & 14 & $\mathrm{H}$ & Cartagena \\
\hline 87 & 14 & $\mathrm{H}$ & Cartagena \\
\hline 88 & 16 & $\mathrm{M}$ & Cartagena \\
\hline 89 & 14 & $\mathrm{M}$ & Cartagena \\
\hline 90 & 15 & $\mathrm{M}$ & Cartagena \\
\hline 91 & 14 & $\mathrm{M}$ & Cartagena \\
\hline 92 & 15 & $\mathrm{M}$ & Cartagena \\
\hline 93 & 14 & $\mathrm{M}$ & Cartagena \\
\hline 94 & 14 & $\mathrm{M}$ & Cartagena \\
\hline 95 & 14 & $\mathrm{H}$ & Cartagena \\
\hline 96 & 15 & $\mathrm{M}$ & Cartagena \\
\hline 97 & 14 & $\mathrm{M}$ & Cartagena \\
\hline 98 & 14 & $\mathrm{H}$ & Cartagena \\
\hline 99 & 14 & $\mathrm{H}$ & Cartagena \\
\hline 100 & 14 & $\mathrm{H}$ & Cartagena \\
\hline 101 & 14 & $\mathrm{H}$ & Cartagena \\
\hline 102 & 14 & $\mathrm{H}$ & Murcia \\
\hline 103 & 14 & $\mathrm{M}$ & Murcia \\
\hline 104 & 14 & $\mathrm{H}$ & Murcia \\
\hline 105 & 13 & $\mathrm{H}$ & Murcia \\
\hline 106 & 15 & $\mathrm{H}$ & Murcia \\
\hline 107 & 14 & $\mathrm{H}$ & Murcia \\
\hline 108 & 13 & $\mathrm{H}$ & Murcia \\
\hline 109 & 14 & $\mathrm{H}$ & Murcia \\
\hline 110 & 14 & $\mathrm{M}$ & Murcia \\
\hline 111 & 14 & $\mathbf{M}$ & Murcia \\
\hline 112 & 12 & $\mathrm{M}$ & Murcia \\
\hline 113 & 14 & $\mathrm{H}$ & Murcia \\
\hline 114 & 14 & $\mathrm{H}$ & Murcia \\
\hline 115 & 13 & $\mathrm{M}$ & Murcia \\
\hline 116 & 14 & $\mathrm{M}$ & Murcia \\
\hline
\end{tabular}

\section{TEST. EDAD SEXO $(*)$ LOCALIDAD}

RESIDENCIA

$\begin{array}{llll}117 & 14 & \text { M } & \text { Murcia } \\ 118 & 12 & \text { H } & \text { Murcia }\end{array}$

$\begin{array}{llll}119 & 13 & \mathrm{H} & \text { Murcia }\end{array}$

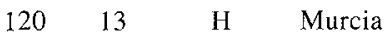

$\begin{array}{llll}121 & 12 & \text { M } & \text { Murcia }\end{array}$

$\begin{array}{llll}122 & 13 & \mathrm{H} & \text { Murcia }\end{array}$

$123 \quad 14 \quad$ M Murcia

$124 \quad 14 \quad$ M Murcia

$\begin{array}{llll}125 & 14 & \mathrm{H} & \text { Nonduermas }\end{array}$

$\begin{array}{lll}126 & 15 & \mathrm{H}\end{array}$

$\begin{array}{llll}127 & 15 & M & \text { Nonduermas }\end{array}$

$\begin{array}{llll}128 & 13 & M & \text { Nonduermas }\end{array}$

$\begin{array}{llll}129 & 14 & \mathrm{H} & \text { Nonduermas }\end{array}$

$\begin{array}{llll}130 & 15 & \mathrm{H} & \text { Nonduermas }\end{array}$

131 $14 \quad \mathrm{M} \quad$ Nonduermas

$\begin{array}{llll}132 & 16 & \mathrm{H} & \text { Nonduermas }\end{array}$

$\begin{array}{llll}133 & 14 & \mathrm{H} & \text { Nonduermas }\end{array}$

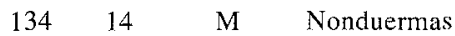

$13514 \quad \mathrm{H}$ Nonduermas

$\begin{array}{lll}136 & 14 & \mathrm{H}\end{array}$ Nonduermas

$137 \quad 13 \quad \mathrm{H} \quad$ Nonduermas

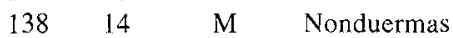

$139 \quad 14 \quad M \quad$ Nonduermas

$140 \quad 14 \quad \mathrm{M}$ Nonduermas

$141 \quad 14 \quad \mathrm{H}$ Nonduermas

$142 \quad 15 \quad M \quad$ Beniajan

$143 \quad 13 \quad \mathrm{H}$ Beniajan

$144 \quad 14 \quad \mathrm{H} \quad$ Beniajan

$145 \quad 14 \quad M \quad$ Beniajan

$\begin{array}{lll}146 & 16 & \mathrm{H}\end{array}$ La Alberca

$\begin{array}{llll}147 & 14 & M & \text { La Alberca }\end{array}$

$148 \quad 16 \quad \mathrm{M} \quad$ La Alberca

$149 \quad 16 \quad M \quad$ La Alberca

$\begin{array}{llll}150 & 16 & \mathrm{H} & \text { La Alberca }\end{array}$

$.151 \quad 16 \quad \mathrm{H} \quad$ La Alberca

$\begin{array}{llll}152 & 15 & \mathrm{H} & \text { La Alberca }\end{array}$

$\begin{array}{llll}153 & 16 & M & \text { La Alberca }\end{array}$

$\begin{array}{llll}154 & 16 & M & \text { La Alberca }\end{array}$

$155 \quad 16 \quad \mathrm{M} \quad$ La Alberca

$\begin{array}{lll}156 & 16 & \mathrm{H}\end{array}$ La Alberca

$\begin{array}{lll}157 & 16 & M\end{array}$ La Alberca

$\begin{array}{llll}158 & 16 & \text { H } & \text { La Alberca }\end{array}$

$\begin{array}{llll}159 & 16 & \mathrm{H} & \text { La Alberca }\end{array}$

$\begin{array}{llll}160 & 15 & \mathrm{H} & \text { La Alberca }\end{array}$

$\begin{array}{lll}161 & 15 & M\end{array}$

$162 \quad 16 \quad \mathrm{M} \quad$ La Alberca

$\begin{array}{llll}163 & 16 & \mathrm{M} & \text { La Alberca }\end{array}$

$\begin{array}{lll}164 & 16 & \mathrm{H}\end{array}$ La Alberca

$\begin{array}{lll}165 & 15 & \mathrm{H}\end{array}$ La Alberca

$\begin{array}{lll}166 & 16 & \mathrm{H}\end{array}$ La Alberca 


\begin{tabular}{|c|c|c|c|c|c|c|c|}
\hline \multicolumn{3}{|c|}{ TEST. EDAD SEXO $\left(^{*}\right)$} & $\begin{array}{l}\text { LOCALIDAD } \\
\text { RESIDENCIA }\end{array}$ & \multicolumn{3}{|c|}{ TEST. EDAD SEXO $\left(^{*}\right)$} & $\begin{array}{l}\text { LOCALIDAD } \\
\text { RESIDENCIA }\end{array}$ \\
\hline 167 & 16 & M & La Alberca & 201 & 16 & $\mathrm{H}$ & Murcia \\
\hline 168 & 15 & $\mathrm{H}$ & La Alberca & 202 & 14 & $\mathrm{H}$ & Murcia \\
\hline 169 & 15 & $\mathrm{H}$ & La Alberca & 203 & 14 & $\mathrm{H}$ & Murcia \\
\hline 170 & 15 & M & La Alberca & 204 & 15 & $\mathrm{M}$ & Murcia \\
\hline 171 & 16 & M & La Alberca & 205 & 16 & $\mathrm{H}$ & Murcia \\
\hline 172 & 15 & $\mathrm{H}$ & La Alberca & 206 & 15 & M & Murcia \\
\hline 173 & 16 & M & La Alberca & 207 & 15 & $\mathrm{M}$ & Murcia \\
\hline 174 & 16 & M & La Alberca & 208 & 16 & M & Murcia \\
\hline 175 & 15 & $\mathrm{H}$ & La Alberca & 209 & 16 & M & Murcia \\
\hline 176 & 16 & M & La Alberca & 210 & 16 & $\mathrm{H}$ & Murcia \\
\hline 177 & 15 & $\mathrm{H}$ & Murcia & 211 & 16 & $\mathrm{H}$ & Murcia \\
\hline 178 & 14 & $\mathbf{H}$ & Murcia & 212 & 16 & $M$ & Murcia \\
\hline 179 & 15 & $\mathrm{H}$ & Murcia & 213 & 16 & $\mathrm{M}$ & La Alberca \\
\hline 180 & 16 & $\mathrm{H}$ & Murcia & 214 & 16 & M & La Alberca \\
\hline 181 & 14 & M & Puente Tocinos & 215 & 16 & M & Puente Tocinos \\
\hline 182 & 14 & $\mathrm{M}$ & Murcia & 216 & 15 & M & La Alberca \\
\hline 183 & 14 & M & Murcia & 217 & 16 & $\mathrm{H}$ & Murcia \\
\hline 184 & 16 & $\mathrm{M}$ & Murcia & 218 & 16 & $\mathrm{M}$ & Murcia \\
\hline 185 & 15 & M & Murcia & 219 & 15 & M & Murcia \\
\hline 186 & 14 & M & Murcia & 220 & 16 & $\mathrm{H}$ & Puente Tocinos \\
\hline 187 & 14 & $\mathrm{M}$ & Murcia & 221 & 12 & $\mathrm{H}$ & Sangonera la Verde \\
\hline 188 & 14 & M & Puente Tocinos & 222 & 12 & M & Sangonera la Verde \\
\hline 189 & 15 & $\mathrm{H}$ & Murcia & 223 & 13 & $\mathrm{H}$ & Sangonera la Verde \\
\hline 190 & 14 & $\mathrm{H}$ & Murcia & 224 & 13 & $\mathrm{M}$ & Sangonera la Verde \\
\hline 191 & 14 & $\mathrm{M}$ & Murcia & 225 & 12 & M & Sangonera la Verde \\
\hline 192 & 13 & M & Murcia & 226 & 12 & M & Sangonera la Verde \\
\hline 193 & 15 & $\mathrm{H}$ & Murcia & 227 & 13 & M & Sangonera la Verde \\
\hline 194 & 15 & $\mathrm{H}$ & Murcia & 228 & 12 & $\mathrm{H}$ & Sangonera la Verde \\
\hline 195 & 16 & M & Murcia & 229 & 12 & $M$ & Sangonera la Verde \\
\hline 196 & 14 & M & Murcia & 230 & 14 & M & Sangonera la Verde \\
\hline 197 & 16 & M & Murcia & 231 & 12 & $\mathrm{M}$ & La Alberca \\
\hline 198 & 14 & $\mathrm{H}$ & Murcia & 232 & 12 & $\mathrm{H}$ & Sangonera la Verde \\
\hline 199 & 15 & M & La Alberca & 233 & 12 & $\mathrm{H}$ & Sangonera la Verde \\
\hline 200 & 15 & M & Murcia & 234 & 12 & $\mathrm{H}$ & Sangonera la Verde \\
\hline
\end{tabular}

(*) $\mathrm{M}=$ mujer, $\mathrm{H}=$ hombre

\section{REFERENCIAS BIBLIOGRÁFICAS}

BORREGO NIETO, Julio (1990): «Norma, variación y enseñanza de la lengua», en El área de Lengua y Literatura en la etapa 12-16, Luis Alcalde Cuevas - Virgilio López Hernández (coord.): Documentos curriculares, CEP Salamanca.

CACIOPPO, John T. - PETTY, Richard E. (1982): «Language variables, attitudes and persuasion», en Attitudes towards Language Variation, Ellen Bouchard Ryan - Howard Giles (ed.), Edward Arnold, London.

DAY, Richard R. (1982): "Children's attitudes toward Language», en Attiutudes towards Language Variation, Ellen Bouchard Ryan - Howard Giles (ed.), Edward Arnold, London. 
DELAMONT, Sara (1984): La interacción didáctica. Cincel-Kaplusz, Madrid.

DE LAS HERAS BORRERO, Jerónimo (1989): «Hacia la programación diferenciada de lenguaje para andaluces-parlantes», en Innovación en la enseñanza de la lengua y la literatura. AA.VV., Ministerio de Educación y Ciencia, Subdirección General de Formación del Profesorado, Madrid.

ESCÁMEZ SÁNCHEZ, Juan - ORTEGA RUIZ, Pedro (1993): La enseñanza de actitudes y valores, Nau Llibres, Valencia.

FERNÁNDEZ, Sonsoles (1987): Didáctica de la gramática. Teorías lingüísticas. Sistemas de la lengua, Narcea, Madrid.

FERRES PRATS, Joan (1989): Recursos videográficos. Reportaje, entrevistas, encuesta, mesa redonda y debate. Alta Fulla, Barcelona.

FIERRO, Alfredo (1985): «Desarrollo social y de la personalidad en la adolescencia», en Psicología evolutiva 3. Adolescencia, madurez y senectud, Mario Carretero, Jesús Palacios, Alvaro Marchesi (compiladores), Alianza, Madrid.

FIERRO, Alfredo (1990): «Desarrollo de la personalidad en la adolescencia», en Desarrollo psicológico y educación I, Jesús Palacios, Alvaro Marchesi, Cisar Coll (compiladores), Alianza, Madrid.

FLAVELL, John H. (1984): El desarrollo cognitivo. Visor, Madrid.

GARCÍA FERNANDEZ, Carmen Rita (1987): «Enfoques didácticos sobre la lengua hablada», en Orientaciones didácticas sobre la lengua, AA.VV., Narcea, Madrid.

GARCÍA MADRUGA, Juan A. (1991): Desarrollo y conocimiento, Siglo XXI, Madrid.

GARCÍA MARCOS, Francisco (1993): Nociones de sociolingüística. Octaedro, Barcelona.

GER VILLA CASTILLO, Enrique (1993): Postmodernidad y educación. Valores y cultura de los jóvenes. Dykinson, Madrid.

GILES, Howard - SMITH, Philip (1979): «Acomodation Theory: Optimal levels of Convergence», en Lenguage and Social Psychology, Howard Giles - Robert St Clair (eds.), Basil Blackwell, Oxford.

GILES, Howard - COUPLAND, Nikolas (1991): Language: contexts and Consequences. Open University Press, Buckingham.

GOFFMAN, Erving (1987): La presentación de la persona en la vida cotidiana. Amorrortu-Murguma, Madrid.

GREGORY, Michael - CARROLL, Susanne (1986): Lenguaje y situación. Variedades del lenguaje y sus contextos sociales. Fondo de Cultura Económica, México.

HALLIDAY, Michael A. K. (1982): El lenguaje como semiótica social. La interpretación social del lenguaje y del significado. Fondo de Cultura Económica, México.

HOPKINS, J. Roy (1987): Adolescencia. Años de transición. Pirámide, Madrid.

HUDSON, Richard Anthony (1981): La sociolingüistica. Anagrama, Barcelona.

IMBERT, Girard (1993): Los escenarios de la violencia. Conductas anímicas y orden social en la España actual. Icaria, Barcelona.

INHELDER, Barbel - PIAGET, Jean (1985): De la lógica del niño a la lógica del adolescente. Paidss, Barcelona.

JIMÉNEZ CANO, José-M. (1986): «La formación lingüística y gramatical en la didáctica de la lengua española», en Anales de Filología Hispánica, volumen 2, Universidad de Murcia. 
KATZ, David (1982): «El enfoque funcional en el estudio de las actitudes», en Estudios básicos de psicología social, Torregrosa, José - Crespo, Eduardo (selección), Hora S.A. - C.I.S., Barcelona.

KRECH, David - CRUTCHFIELD, Richard - BALLACHEY, Egerton (1978): Psicología social. Biblioteca Nueva, Madrid.

LAMBERT, Wallace E. (1979): "Language as a Factor in Intergroup Relations», en Language and Social Psychology. Howard Giles - Robert St Clair (eds.), Basil Blackwell, Oxford.

OVEJERO BERNAL, Anastasio (1988): Psicología social de la educación. Herder, Barcelona.

OVEJERO BERNAL, Anastasio (1990): El aprendizaje cooperativo. Una alternativa eficaz a la enseñanza tradicional. PPU, Barcelona.

PAIS, Cidmar Teodoro (1983): «Essai de formalisation des tensions dialectiques: culture, societi, systhmes simiotiques», en Semiotics unfolding: Proceding of the Second Congress of the International Association for Semiotic Studies. Tasso Borbe (ed.), Mouton, Berlin.

REARDON, K. K. (1983): La persuasión en la comunicación. Teoría y contexto. Paidós, Barcelona.

ROMAINE, Suzanne (1984): The Language of Children and Adolescents. The Acquisition of Communicative Competence. Basil Blackwell, Oxford.

RYAN, Ellen - GILES, Howard - SEBASTIAN, Richard (1982): «An integrative perspective for the study of attitudes toward Language», en Attitudes towards Language Variation. Ellen Bouchard Ryan - Howard Giles (eds.), Edward Arnold, London.

STUBBS, Michael (1987): Lenguaje y escuela. Análisis sociolingüístico de la enseñanza. Cincel-Kapelusz, Madrid.

TITONE, Renzo (1986): El lenguaje en la interacción didáctica. Narcea, Madrid.

WOBER, J. Mallory (1990): «Language and Television», en Handbook of Language and Social Psychology. Howard Giles - W. Peter Robinson (eds.): John Wiley, Chichester.

ZAYAS, Felipe (1987): Propuesta curricular de Lengua Castellana . Enseñanza Secundaria Obligatoria. Generalitat Valenciana. Conselleria de Cultura, Educació i Ciencia. 